\title{
LA SÁTIRA GRÁFICA DE CALPURNIOY EL ROTO SOBRE LA DIGITALIZACION SOCIAL: un análisis crítico desde la perspectiva de las competencias digitales
}

\author{
A SÁTIRA GRÁFICA DE CALPURNIO E EL ROTO \\ SOBRE A DIGITALIZAÇÃO SOCIAL: \\ un análisis crítico sob a ótica das competências digitais
}

CALPURNIO AND EL ROTO'S GRAPHIC SATIRE ON SOCIAL DIGITIZATION:
a critical analysis from the perspective of digital competences

José-Antonio Gómez-Hernández ${ }^{1}$

Antonio-Raúl Fernández-Rincón ${ }^{2}$

\begin{abstract}
RESUMEN
La digitalización masiva y acelerada supone una transformación enorme de nuestra vida privada y nuestra actividad social, con repercusiones personales, políticas y económicas. Este fenómeno de digitalización de la vida debe ser comprendido por la ciudadanía, y por ello requiere competencia informacional y pensamiento crítico. Una de las formas de fomentar la reflexión crítica sobre la sociedad digital es la sátira gráfica, y por ello el objetivo de este trabajo es exponer cómo han tratado este tema los dos principales autores españoles: Calpurnio y El Roto. La metodología ha consistido en la búsqueda e identificación de viñetas, clasificándolas por sus críticas al abuso de las tecnologías de la información y sus consecuencias, teniendo como referencia para el análisis principalmente el Marco Europeo de la Competencia Digital. Concluimos que los principales riesgos que aparecen en la sátira gráfica son la incapacidad para organizar la información, la conexión excesiva que conlleva dependencia digital, la desinformación y vulnerabilidad a las noticias falsas, que facilita manipulación política y económica, la cesión irresponsable de datos y su uso incorrecto, la pérdida de privacidad o el deterioro de las relaciones interpersonales. La sátira sobre la digitalización no pretende la tecnofobia, sino un necesario pensamiento crítico desde el humor, y prevenir riesgos por la adopción irreflexiva de la tecnología sin competencia para su uso consciente, reflexivo e intencional.

Palabras clave: sátira gráfica. El Roto. Calpurnio. competencia digital. competencia informacional, riesgos digitales
\end{abstract}

\begin{abstract}
Massive and accelerated digitization represents a huge transformation of our private life and our social activity, with personal, political and economic repercussions. This phenomenon of digitization of life must be understood by citizens, and for it need informational competence and critical thinking. One of the ways to promote critical reflection on the digital society is graphic satire, and for this reason the objective of this work is to expose how the two main Spanish authors Calpurnio and El Roto have treated this subject. The methodology has been the search and identification of bullets, classifying them for their criticism of the abuse of information technologies and their consequences, having as a framework for analysis the European Digital Competence Framework for Citizens. We conclude that the main risks that appear in the graphic satire are the inability to organize information, the excessive connection that digital dependence entails, the disinformation and vulnerability to false news, which facilitates political and economic manipulation, the irresponsible transfer of data and its incorrect use, loss of privacy or deterioration of interpersonal relationships. The satire on digitization does not pretend technophobia, but a necessary critical thought from humor, and to prevent risks due to the thoughtless adoption of technology without competence for its conscious, reflective and intentional use.
\end{abstract}

Keywords: graphic satire. El Roto. Calpurnio. digital competence. informational competence, digital risks.

Artigo submetido em 17/05/2020 e aceito para publicação em 27/11/2020

1 Catedrático de Bibliteconomía. Director das Ediciones. Universidade de Murcia, Espanha. ORCID https://orcid.org/0000-0003-45321142. E-mail: jgomez@um.es

2 Professor associado na Facultade de Comunicação e Documentação. Universidade de Murcia, Espanha. ORCID https://orcid. org/0000-0001-7143-2175. E-mail: antonioraul.fernandez@um.es 


\section{INTRODUCCIÓN}

La digitalización masiva y acelerada de la vida privada y social supone una transformación enorme con repercusiones personales, políticas y económicas. La tecnología capta y atrapa nuestra atención, cambia nuestras formas de comunicarnos y relacionarnos, de producir y consumir en el marco de la Industria 4.0, nuestras formas de acceder y usar información en las distintas facetas de la vida, nuestras formas de participación política o nuestras formas de aprender. La reflexión crítica de sus posibilidades y problemas no debe evitarse, pues incurriríamos en una actitud de tecnofilia exagerada e ingenua, sin cuestionar los riesgos incluidos en la pérdida de privacidad, el abuso de los datos personales, la virulencia de las noticias falsas o la vulnerabilidad a la manipulación política, económica, ambiental o sanitaria.

Una de las vías para fomentar la reflexión crítica sobre la sociedad digital es el humor, especialmente el que adquiere el tono de sátira gráfica, y en este trabajo queremos exponer cómo la han desarrollado, en distinto grado de acidez, dos de los autores españoles más relevantes en este género: Eduardo Pelegrín, que usa el pseudónimo Calpurnio para dibujar su personaje Cuttlas, y Andrés Rábago, conocido principalmente como El Roto. Como veremos, uno alude más a las consecuencias del uso de la tecnología en la organización de la vida personal y de las carencias que solemos tener en el ámbito de la competencia digital, en sus facetas más instrumentales. El segundo autor aporta una perspectiva más sarcástica y global sobre las consecuencias políticas y sociales de la digitalización masiva que está teniendo lugar sin una perspectiva crítica.

El fin de las viñetas satíricas sobre lo digital no creemos que sea promover la tecnofobia, sino el cuestionamiento de algunas de las consecuencias de la tecnología, algo muy necesario en sociedades complejas a las que se atribuye un carácter "líquido" (BAUMAN, 2007). En ese sentido, a partir del análisis de lo que aportan estos dos autores, nos plantearemos si a través de su obra se puede deducir una categorización intuitiva de los "riesgos digitales" que estamos sufriendo. Y a partir de ello sugeriremos su empleo para prevenir algunos de los mismos en el marco de los programas formativos de la competencia digital de la ciudadanía que realizan instituciones culturales como las bibliotecas.

\section{LA SÁTIRA GRÁFICA}

\subsection{Rasgos definitorios}

La sátira es un género literario milenario, que se remonta a los filósofos y comediógrafos clásicos griegos, que encontraron en ella una forma de criticar costumbres y conductas sociales desde el punto 
de vista moral. Para hacerlo aplicaban el humor, el sarcasmo, la ironía, la hipérbole en muchos casos o la parodia, consiguiendo así mostrar una postura crítica respecto una realidad que desaprobaban y querían denunciar o cuestionar.

En su dimensión gráfica o visual, se comenzó a expandir como medio de expresión idóneo a partir de la imprenta y la prensa moderna, y fue trasladándose desde los lienzos y grabados de artistas como William Hogarth, James Gillray, George Cruikshank o Honoré Daumier a los nuevos medios escritos, dando lugar a las viñetas satíricas conforme se desarrollaban el Estado moderno, la ciudadanía, Ios sistemas de representación política y la opinión pública a finales del siglo XIX y principios del XX. Con ello se fue convirtiendo en una forma de periodismo con la capacidad del bisturí para penetrar con precisión en los problemas sociales.

Este género de humor usa principalmente dos formatos: la viñeta única y la tira humorística. Ambas buscan solucionar de maneras distintas un importante desafío: lograr sintéticamente una trama completa y autoconclusiva (MARTIGNONE; PRUNES, 2008). La viñeta es el medio que más se identifica con el lenguaje del cómic, al ser la representación pictográfica del mínimo espacio o/y tiempo significativo de una historieta (GUBERN, 1972) y pretende condensar una situación de forma comprensible, suponiendo el clímax de la situación humorística (PITRI, 2011). En la tira humorística, en cambio, la situación se cuenta mediante dos o más cuadros, siendo su estructura narrativa y sintáctica deudora de la técnica cinematográfica, si bien a diferencia de ésta no pretende resolver una serie de cuadros inmóviles en un continuo, sino que genera una continuidad ideal a través de una real discontinuidad que el lector debe reconstruir (ECO, 1965). La tira exige una construcción secuencial que disgrega el continuum narrativo en unos pocos elementos indispensables, entremezclados con omisiones pertinentes y necesarias para lograr el efecto sintético característico (MCCLOUD, 2007).

La sátira gráfica se configuró como un medio idóneo para la crítica política y el periodismo de opinión, y en el plano simbólico ha ido evolucionado tendiendo siempre a "comunicar más con menos" (BARRER0, 2014), en línea con corrientes estéticas del siglo XX como la simplificación icónica y la esquematización. En el plano ideológico, si durante la llustración y la Edad Moderna fue sobre todo una propuesta reactiva contra el poder opresor y la falta de libertades, ya más recientemente se ha ido incorporando a estas creaciones gráficas el escepticismo y el nihilismo para combatir la esquizofrenia de las sociedades mediáticas.

\subsection{Referentes destacados}

Actualmente, aunque la prensa constituye un medio de difusión relevante para laviñeta satírica, ésta se disemina también a través del conjunto del ecosistema mediático: ilustradores, guionistas, pintores 0 artistas gráficos despliegan su obra en páginas web, blogs, redes sociales, galerías de arte 
o los propios muros de la ciudad. Han recogido el testigo de los primeros humoristas gráficos de prensa creadores como Pawel Kuczynski, Andrei Budayev, Lora Zombie o el artista británico Banksy (GONZALEZ-GARCÍA; CHACÓN-LÓPEZ, 2018).

Al incorporarse a la sociedad digital circulando por ella, la sátira gráfica quizás ha ido perdiendo parte de su capacidad de ofender en ese magna en que se han convertido las redes sociales, en las que Ios propios usuarios como prosumidores difunden todo tipo de contenidos humorísticos sobre la vida política y social (BERROCAL, CAMPOS-DOMÍNGUEZ, REDOND0, 2014)

Figura 1 - Steve Cutts

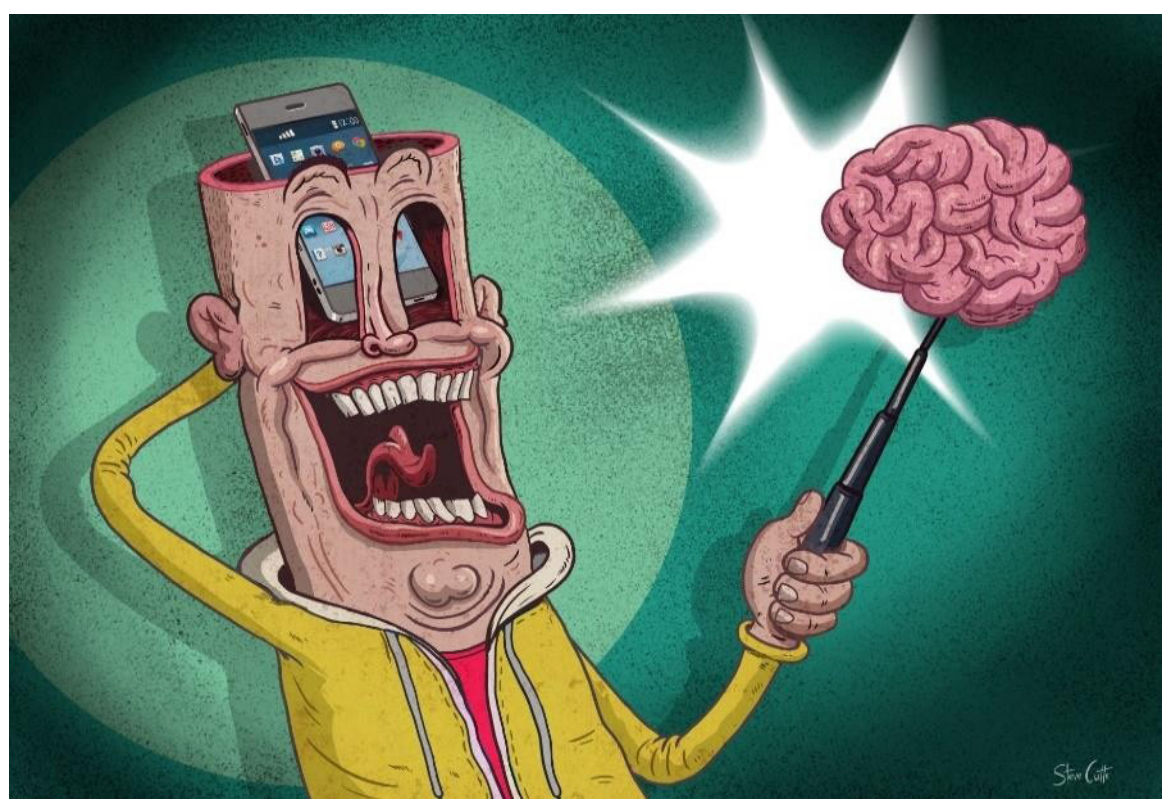

Fuente: En: stevecutts.com

Pero, a su vez, lo digital se ha convertido en una de las temáticas más recurrentes de este género de opinión, pues es preocupación generalizada lo que está suponiendo en las dinámicas y nuevos hábitos sociales, la modificación de costumbres y la nueva cotidianidad, mediatizada por las tecnologías, que pueden implicar peligros en los procesos de comunicación e interacción humana.

Como ejemplos de esta línea de atención a lo digital en viñetas satíricas encontramos a artistas como el citado Kuczynski, Steve Cutts (stevecutts.com) (Fig. 1), Jean Jullien (jeanjullien.com) (Fig. 2), John Holcroft (johnholcroft.com), Marc Kostabi (mkostabi.com), Liam Walsh (liamfranciswalsh.com), Renn (ritsch-renn.com), Asaf Hanuka (asafhanuka.com), Gerhard Haderer (\#gerhardhaderer), Marco Melgrati (society6.com/melgratillustrator) oÁngel Boligán (www.boligan.com) (Fig. 3).

Figura 2 - Jean Julien 


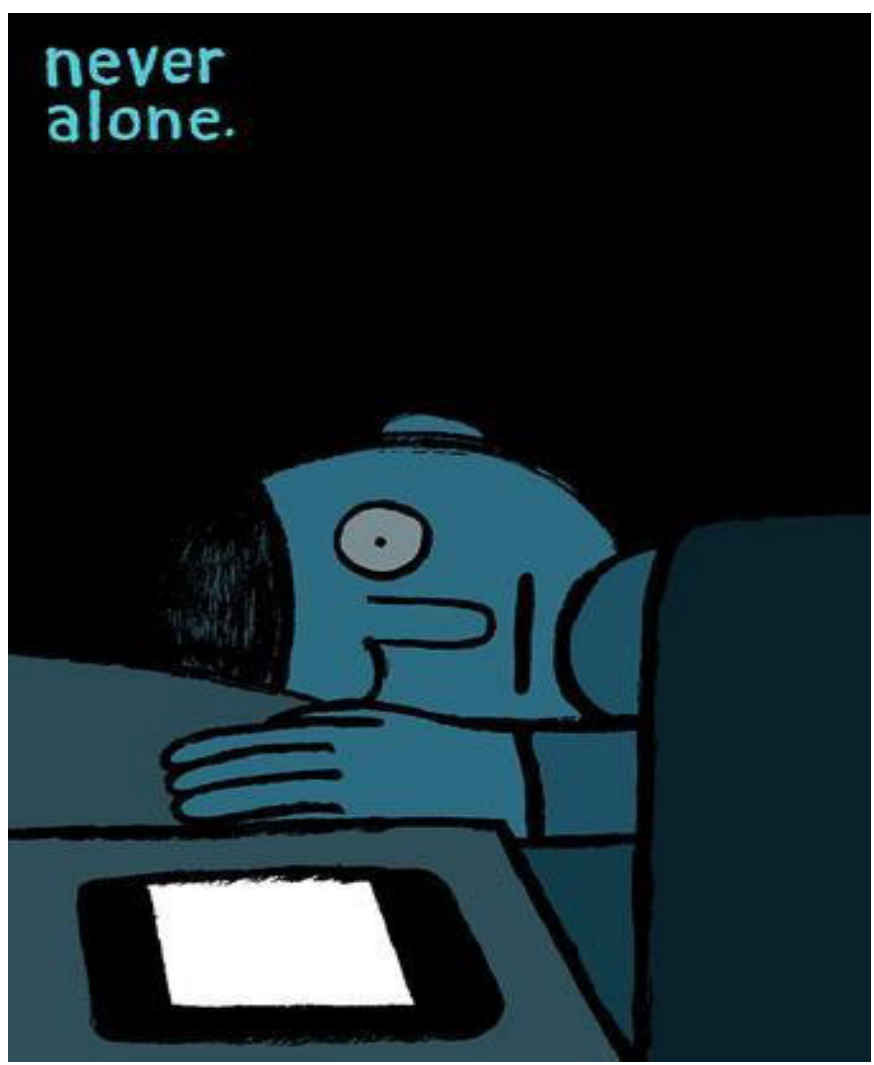

Fuente: En jeanjullien.com

Figura 3 - Ángel Bolligan

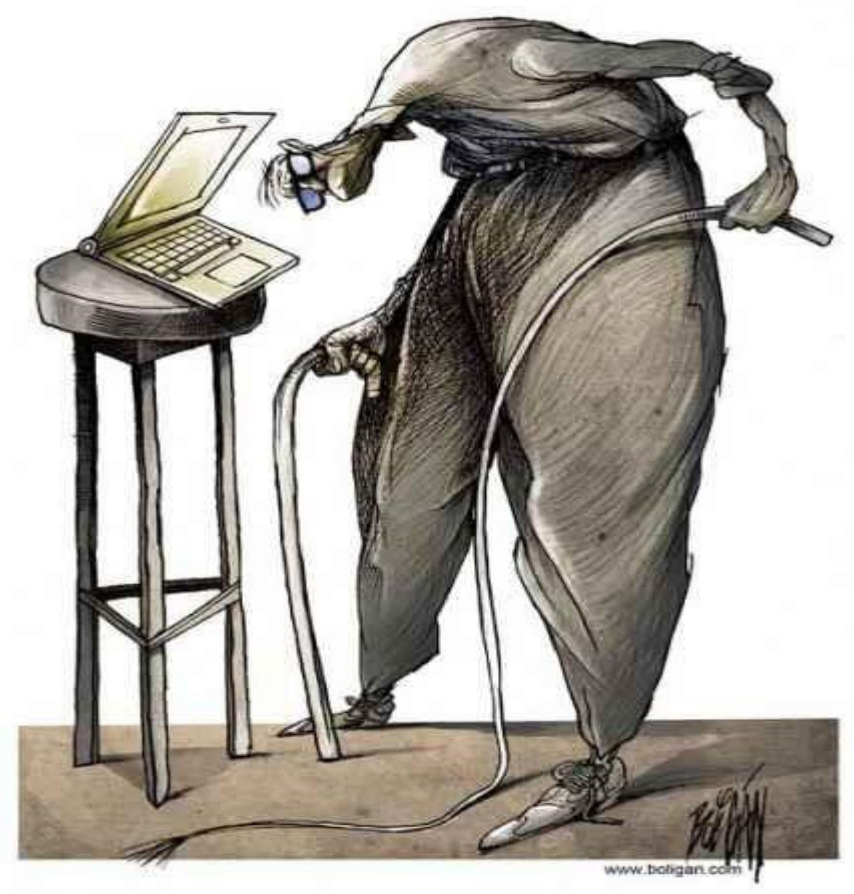

Fuente: En: www.boligan.com 
Si nos centramos en España, los últimos años de la Dictadura franquista y la Transición democrática impulsaron a una gran generación de artistas gráficos cuya labor en el terreno del humor gráfico se había visto constreñida, y en la que El Perich (1941-1995) o Chumy Chúmez (1927-2003) fueron maestros destacados. Peñamarín (2002) sostiene que el humor gráfico contribuyó durante el final del Franquismo a que muchos españoles afrontaran la comprensión de su época, y Meléndez Malavé (2005) les atribuye un rol relevante en la formación de la opinión pública durante la Transición.

La proliferación en aquel momento de revistas y publicaciones de humor satírico y la inclusión de espacios más o menos estables en las cabeceras de ámbito nacional hizo aflorar el talento de numerosos artistas que pudieron desplegar su obra con absoluta libertad en la nueva realidad política española, y hacer llegar a audiencias amplias la sátira, el humor y la crítica ácida sobre asuntos políticos, sociales y culturales.

Son muchísimos los ilustradores que han ido haciendo humor en España sobre la sociedad de la información conforme ésta evolucionaba, cuestionando el papel de la prensa, la televisión, la publicidad, la lectura y el libro, la telefonía, Internet o las redes sociales. Una exposición de Vodafone (2007), centrada en las viñetas cómicas sobre el uso personal y social de los dispositivos móviles, seleccionó una muestra de 56 ilustradores, lo que nos da un indicio de la amplia presencia de la tecnología digital en el humor de los creadores españoles.

Si la figura clave en la ironización gráfica amable sobre el mundo de la comunicación social fue Antonio Fraguas, Forges (1942-2011) (Fig. 4), sobre la cuestión digital quienes que más han publicado en los últimos años han sido Andrés Rábago (ElRoto), Mauro Entrialgo, Calpurnio, Eneko, Miguel Brieva y más recientemente Flavita Banana.

Figura 4 - Forges

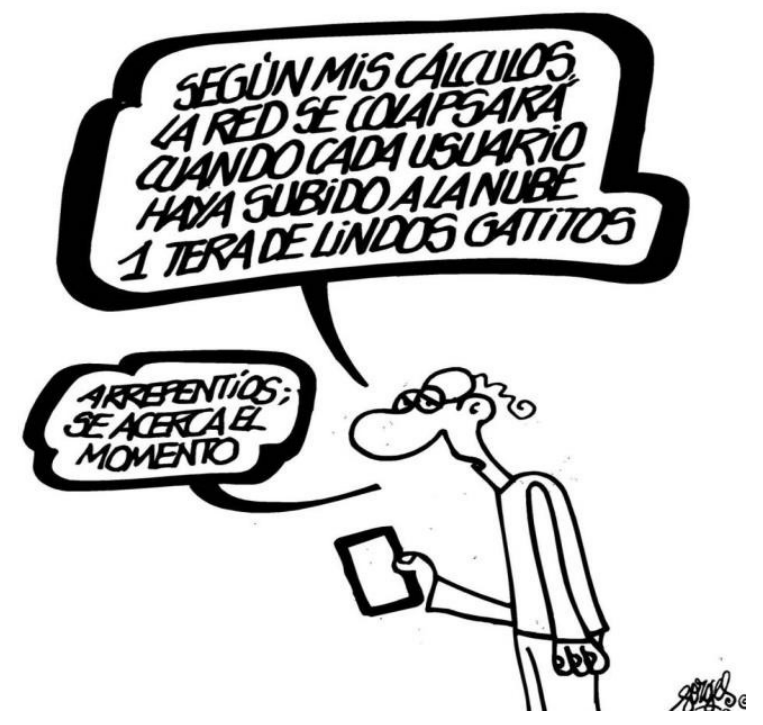

Fluente: El País (17 de junio 2017) 
Andrés Rábago (MADRID, 1947) es uno de los ejemplos más brillantes del humor gráfico y satírico en España, y a lo largo de su carrera ha colaborado en revistas emblemáticas como Hermano Lobo, La Codorniz, Triunfo, Madriz, El Jueves, y periódicos como Diario16, El Independiente, El Periódico de Cataluña o El País, bajo pseudónimos como Ops, Jonás,

Ubú y El Roto. En 2012 obtuvo el Premio Nacional de Ilustración del Ministerio de Cultura de España como autor de más de más de una veintena de libros, en los que ha recogido su obra como viñetista y artista gráfico, de la que es muestra brillante su exposición en el Museo Nacional del Prado No se puede mirar y otras estampas (RÁBAGO, 2019) inspirada en Goya. Eduardo Pelegrín (ZARAGOZA, 1959), conocido como Calpurnio, es el artista multimedia creador del personaje Cuttlas, un "vaquero samurái" con forma de monigote cuyas andanzas nacieron en 1983 en el fanzine El Japo de su ciudad natal. Las viñetas e historietas de El Bueno de Cuttlas han aparecido en Makoki, El Víbora, El País (hasta 2001) y después en 20 minutos y Valencia Plaza.

\section{Figura 5 - Desinformación}

\section{DES INFORMACION}

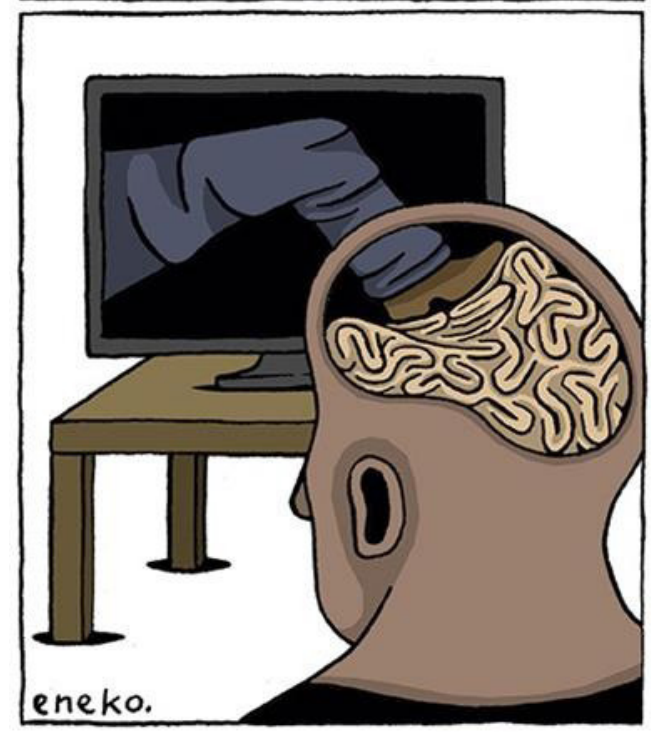

Fuente: Eneko (2014)

Eneko de las Heras (CARACAS, 1963) (Fig. 5) ha colaborado, tras ocho años de creación profesional en su país, en periódicos gratuitos como 20 minutos y después en publicaciones como Interviú, El Jueves, Diagonaly el diario Egin. Autor de estilo directo, contundente e incisivo, sus creaciones mezclan humor ácido y compromiso social, siendo usadas como un medio de cuestionamiento y no un 
fin en sí mismas. Su dibujo es limpio, nítido y desprovisto de contenido textual, abordando temáticas clave de la sociedad contemporánea como la corrupción, las migraciones, la ecología, y la comunicación en algunas ocasiones. Desde 2017 publica en un blog del diario 20 minutos llamado Sancho en su isla (https://blogs.20minutos.es/eneko/).

Mauro Entrialgo (VITORIA, 1965) (Fig. 6), es un ilustrador, dramaturgo, músico, artista gráfico e historietista que comenzó publicando en Makoki y ha dibujado para los diarios Público y El País y en revistas satíricas como El Jueves o Mongolia.

Figura 6 - Silvia los tiempos adelantan

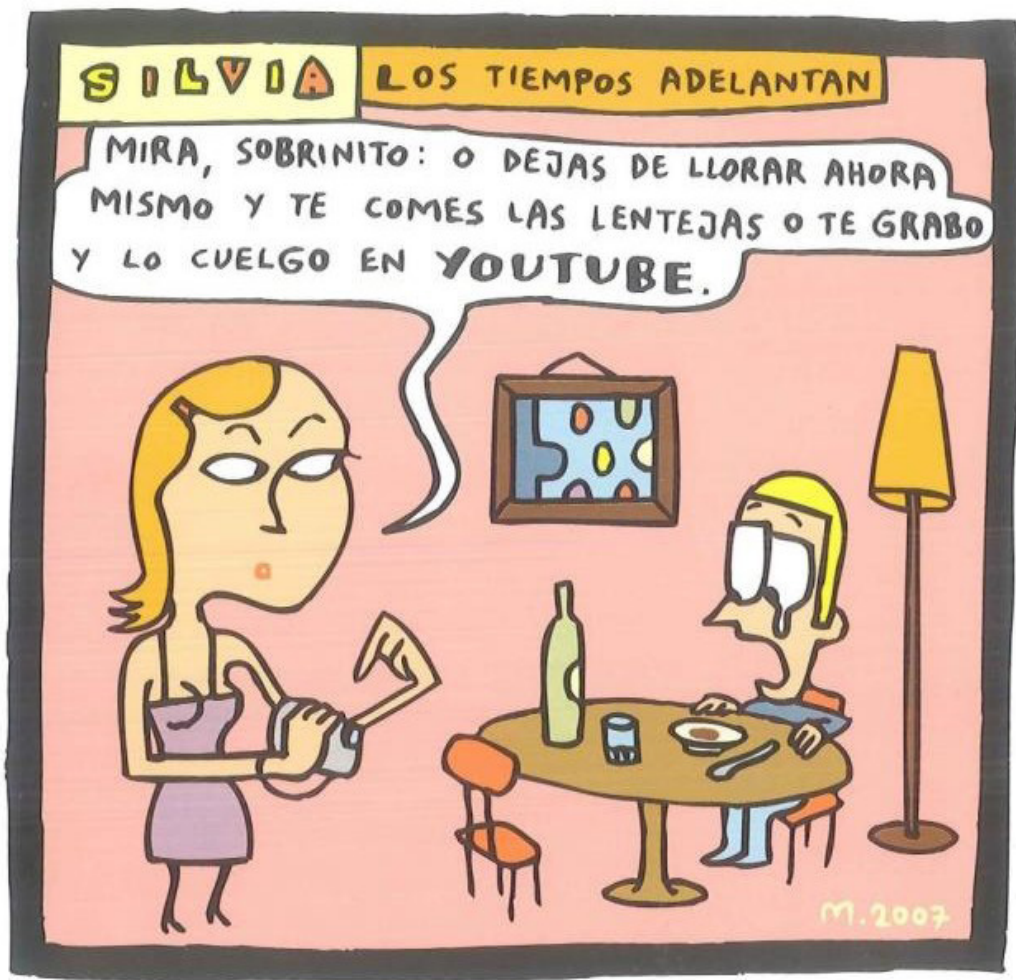

Fuente: Mauro Entrialgo (2015)

En relación con la conducta digital y sus repercusiones sociales publicó Interneteo y Aparatuquis (2015), recopilación de las viñetas publicadas en la versión digital de El País desde 2007, caracterizadas por un dibujo sencillo que pone en evidencia comportamientos que deben hacernos reflexionar. En sus composiciones destacan los personajes conversando mediante textos largos que, a menudo, componen una estructura narrativa completa.

Miguel Brieva (Sevilla, 1974) (Fig. 7) comenzó en la revista autoeditada Dinero, y ha publicado en La Vanguardia, El País, Cinemanía, Rolling Stone, Ajoblanco o El Jueves. 
Figura 7 - Un Buen dia en todos los terminales

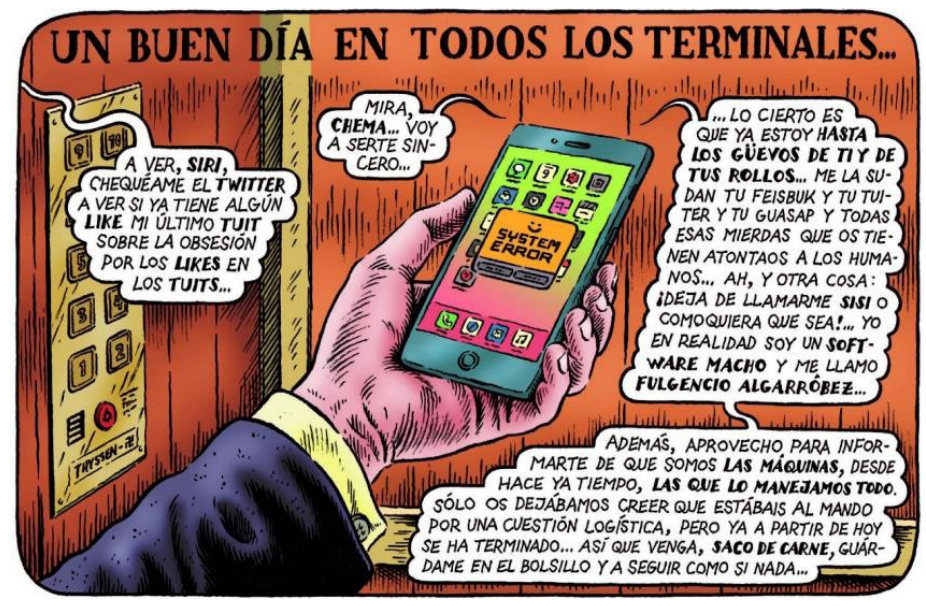

Fuente: En: Miguel Brieva (2017)

Su trabajo se inspira en la iconografía americana de mediados del siglo XX, con dibujos detallistas, colores y elementos añadidos que se acompañan de textos, casi siempre aforismos o definiciones creativas sobre determinadas situaciones o comportamientos. Entre temas recurrentes como la crítica y humor ácido del consumismo, la educación o la religión, está la sociedad digital. Su intención es una crítica del mundo contemporáneo abogando por la educación como medio y fin para la consecución de un mundo mejor, un lugar para regenerar la especie y combatir el poder de las élites políticas y económicas. Entre sus obras publicadas destaca La gran aventura humana (2017), una recopilación de trabajos gráficos sobre temáticas como el cambio climático, la crisis energética, el colapso financiero, el consumismo, el individualismo y los problemas derivados de la sobrexposición digital.

Flavia Álvarez-Pedrosa (OVIED0, 1987) (Fig. 8) es una ilustradora que firma sus dibujos como Flavita Banana. Actualmente publica en El País sus viñetas, que han sido compiladas en Archivos estelares (2017) y Archivos cósmicos (2019).

Figura 8 - Flavita Banana

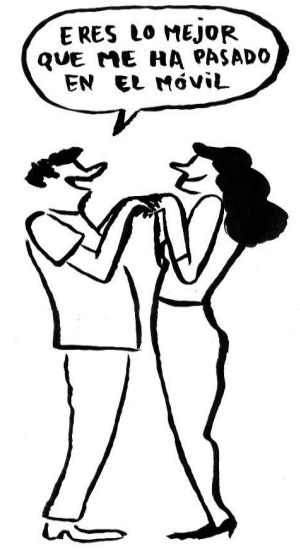

FLANiTA

Fuente: Flavita Banana (2019) 
Esta autora disecciona las relaciones humanas o las contradicciones de la sociedad digital con un tono irónico y un dibujo muy simplificado y minimalista, que en cierto modo parece heredar el estilo de El Roto. Su obra puede seguirse al día por su presencia en los medios digitales a través de cuentas en redes sociales como Facebooke Instagram y su web flavitabanana.com.

\section{OBJETIVOS Y METODOLOGÍA}

Como se ha anticipado, el objetivo de este trabajo es describir y categorizar la visión crítica de la sátira gráfica española acerca de la intensa digitalización que se ha producido en la sociedad contemporánea. Complementariamente, pretendemos indicar algunas posibilidades de utilización de las viñetas cómicas en programas de formación de la competencia informacional y digital de la ciudadanía, por su contribución al debate sobre su interpretación y el pensamiento crítico. Aunque la historieta 0 cómic se ha usado profusamente en programas educativos de enseñanza de la Historia, de divulgación científica o sensibilización social, y la compresión de las imágenes y su lenguaje forman parte de la alfabetización visual, no nos consta el uso de las viñetas satíricas de temática tecnológica en actividades de formación de competencias digitales críticas. Por ello pretendemos validar en próximos trabajos su aplicabilidad incluyéndolas en sesiones bibliotecarias sobre bienestar y prevención de riesgos digitales.

Una vez revisada la obra de los principales dibujantes españoles, disponible tanto a través de recopilaciones como en sus páginas personales y en los portales en Internet de los periódicos donde publican, optamos por centrarnos en Calpurnio y El Roto. La elección de estos creadores se basa en las siguientes razones: a) tienen una extensa trayectoria en algunos de los medios de comunicación escrita de mayor alcance nacional; b) es posible el acceso abierto a sus viñetas en las webs en que se publicaron (por ejemplo, el digital 20minutos y El País); c) tratan muy ampliamente las cuestiones digitales en su humor; y d) la crítica que realizan es muy complementaria, al centrarse el primero más en lo individual y el segundo en lo social.

La siguiente tarea metodológica consistió en la obtención y clasificación de la obra sobre tecnología digital de ambos dibujantes. Para ello utilizamos en el caso de Calpurnio sus publicaciones, especialmente la editada en 2017, y su blog personal (https://Calpurnio.blogspot.com). Y sobre El Roto consultamos su sección en el portal en Internet de El País (https://elpais.com/autor/el-roto/) extrayendo las viñetas sobre la temática objeto de investigación del periodo entre 2010 a marzo de 2020. 
Para el análisis de su contenido se tomó como referencia el Marco Europeo de la Competencia Digital (FERRARI, 2013), la visión integral de la competencia informacional y digital como una metaalfabetización según el enfoque de Jacobson \& Mackey (2013), y la reciente definición de la alfabetización informacional realizada por CILIP (2018). El Marco Europeo describe en qué consiste tener una adecuada competencia digital como ciudadanos en la sociedad de hoy, y por eso nos pareció interesante confrontar las críticas, carencias o errores que las viñetas contienen con los conceptos, habilidades y valores que este modelo determina. Aunque el modelo llega a formular veintiuna subcompetencias, en este estudio intentamos relacionar las viñetas con sus cinco principales áreas competenciales: 1) la búsqueda, uso y organización de la información; 2) la comunicación y colaboración en contextos digitales; 3) la creación de contenidos; 4) los aspectos éticos y de seguridad, y 5) la capacidad de resolución de problemas en este ámbito.

Complementariamente, consideramos como referente de análisis de la sátira gráfica el enfoque de la meta-alfabetización por asumir la complejidad de la sociedad digital, con sus múltiples canales y medios de información masiva, así como la visión de CILIP por ser muy acorde a las cuestiones políticas y sociales que trata este humor: es una visión holítica de la competencia informacional porque integra entre sus componentes clave la conciencia crítica y el pensamiento crítico, la comprensión de los aspectos éticos y políticos y su relevancia para todos los ámbitos de la vida, desde la salud, la economía, la sostenibilidad o la participación ciudadana, vinculándola al empoderamiento y la equidad.

\section{CALPURNIO: UNA CRÍTICA MINIMALISTA DE LOS COMPORTA- MIENTOS DIGITALES}

Calpurnio trata temáticas que van desde la ciencia ficción, la filosofía o la metafísica hasta la tecnología. Con unos trazos de apariencia infantil, sus personajes y situaciones son reducidos a la mínima expresión gráfica, dibujados con plumilla o tinta china y ocasionales adiciones de color con acuarela o técnicas digitales. Con El bueno de Cuttlas aplica un tono suave, basado en la ironía y la simplicidad, para poner de manifiesto problemas y contradicciones del sujeto contemporáneo.

Una primera llamada de atención de Calpurnio sería acerca de la complejidad de organizar y gestionar los contenidos personales que acaparamos en el contexto digital (Fig. 9 y 10). 
Figura 9 y 10 - Calpurnio

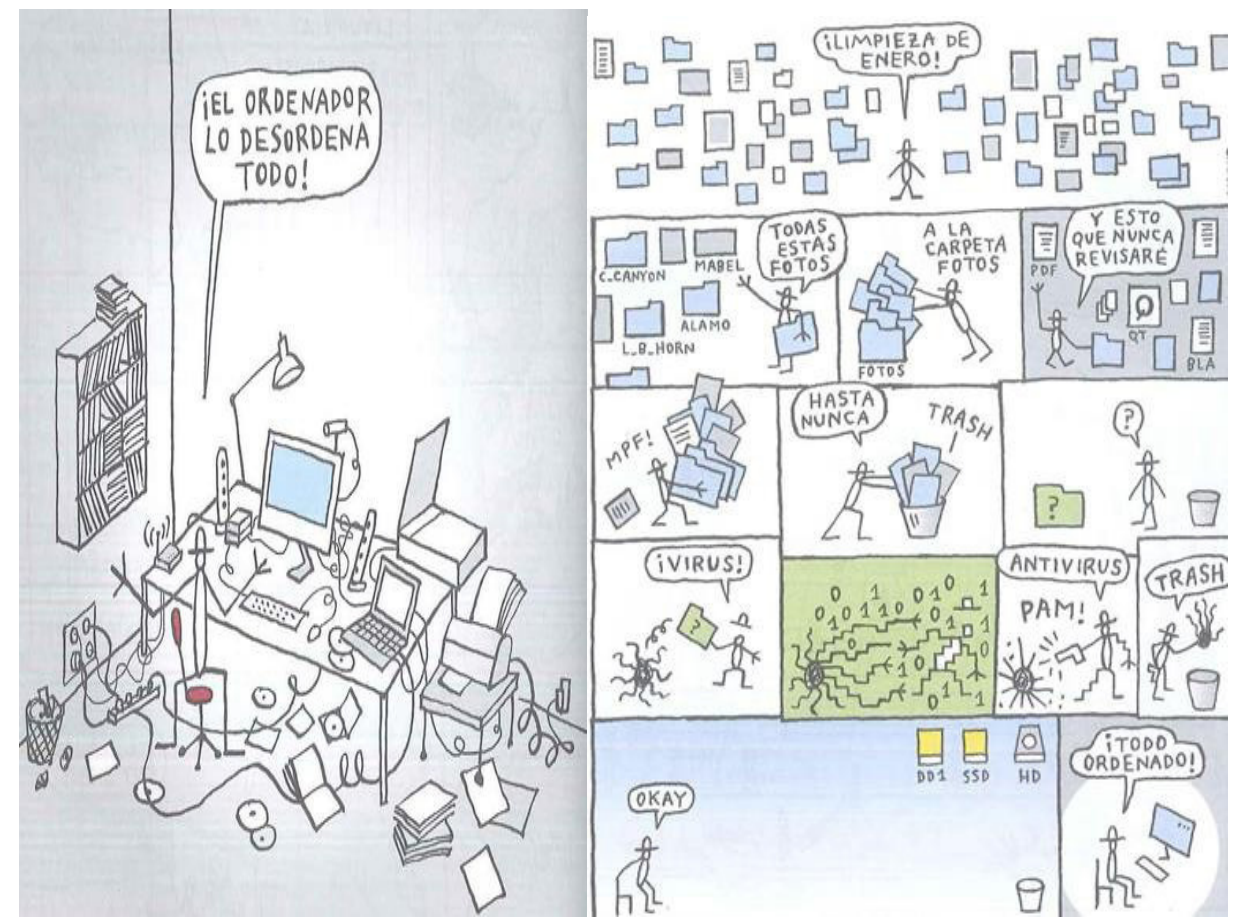

Fuente: Calpurnio (2017)

Una segunda cuestión vinculada a la primera es la de la falta de seguridad: Cuttlas es consciente de los posibles ataques a nuestra información y a los dispositivos de los hackers, y lo representa mediante una lucha de su personaje vaquero con los peligros digitales (Fig. 11).

Figura 11 - Calpurnio

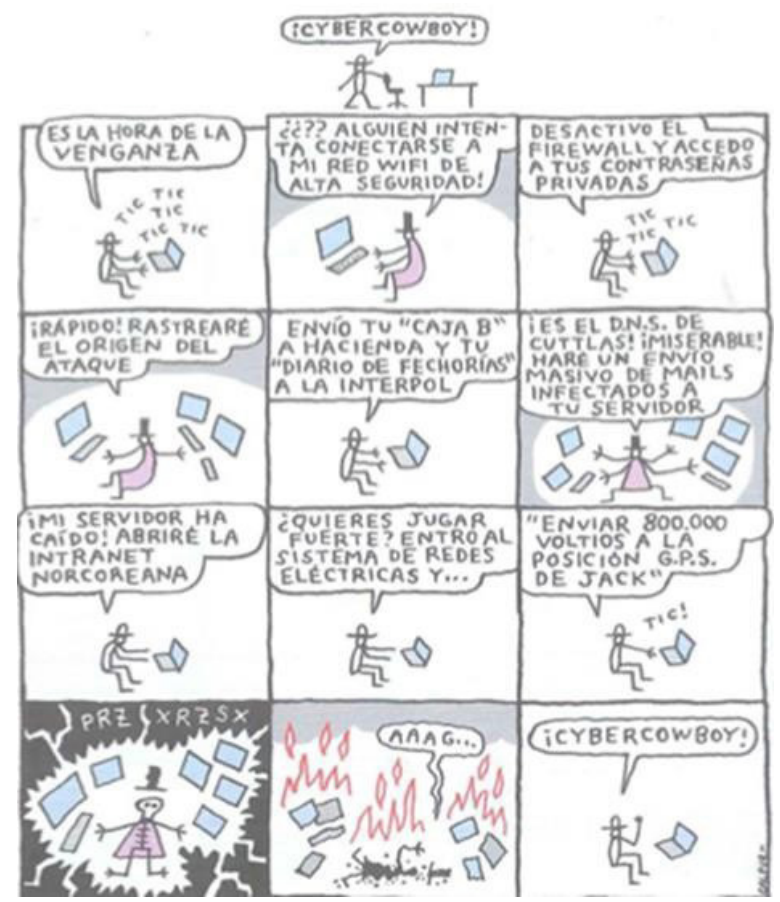

Fuente: Calpurnio (2017) 
En tercer lugar, Cuttlas hace autocrítica en lo referido al consumismo tecnológico exacerbado, que nos lleva a renovar de forma constante y acrítica los dispositivos tecnológicos, y no va acompasado con un aprovechamiento de las supuestas posibilidades de cada nueva versión de un producto, o la intrascendencia real de algunas de las novedades que las tecnologías nos ofrecen para obligarnos a renovarlas constantemente (Fig. 12 y 13).

Figura 12 y 13 - Calpurnio

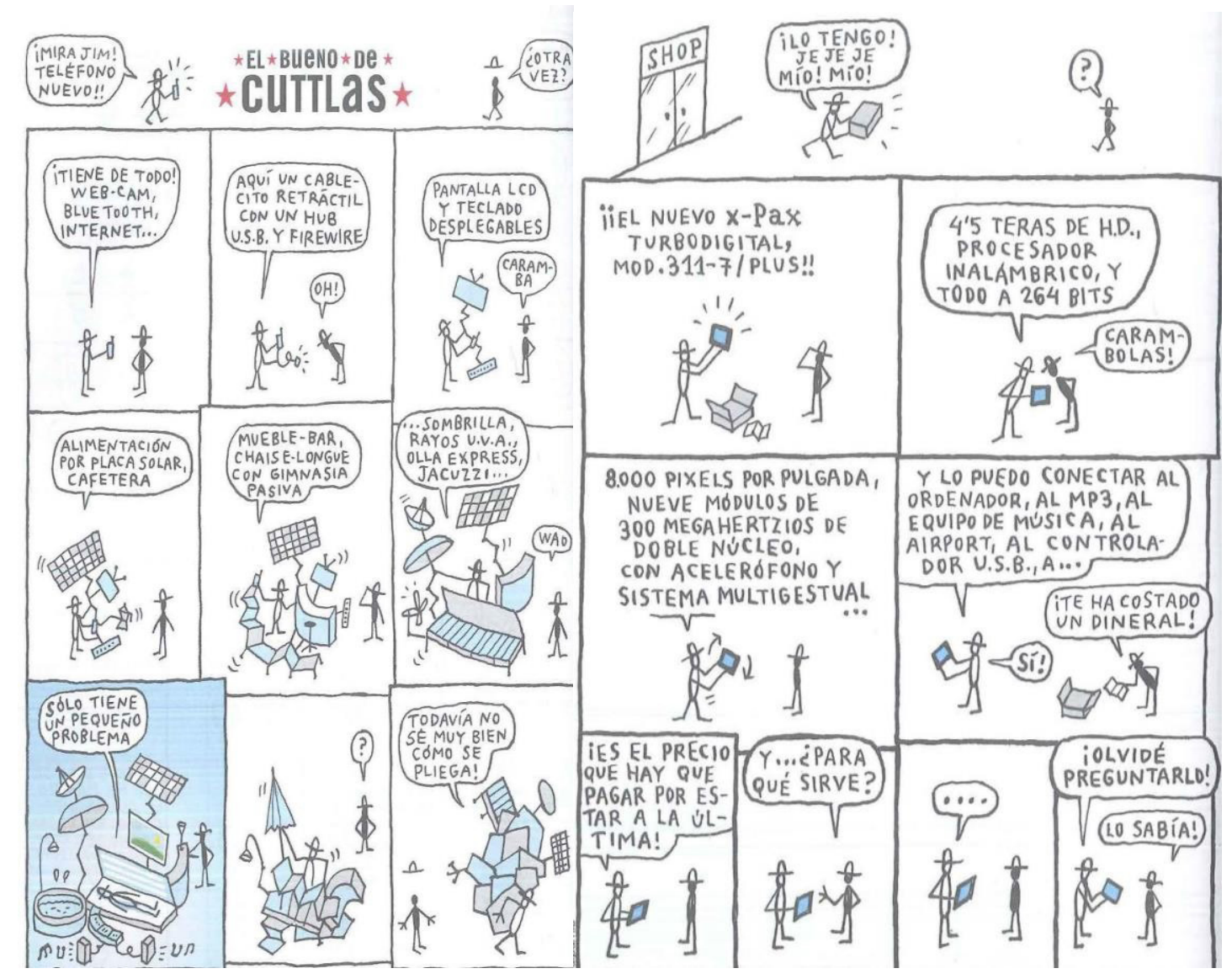

Fuente: Calpurnio. (2017)

Pero la dependencia no conlleva solo un problema de consumismo de las herramientas tecnológicas, sino que esto implica también una valoración excesiva de lo que supone en nuestra vida, atribuyéndole un protagonismo absoluto (Fig. 14 y 15). 
Figura 14 y 15 - Calpurnio (2017)

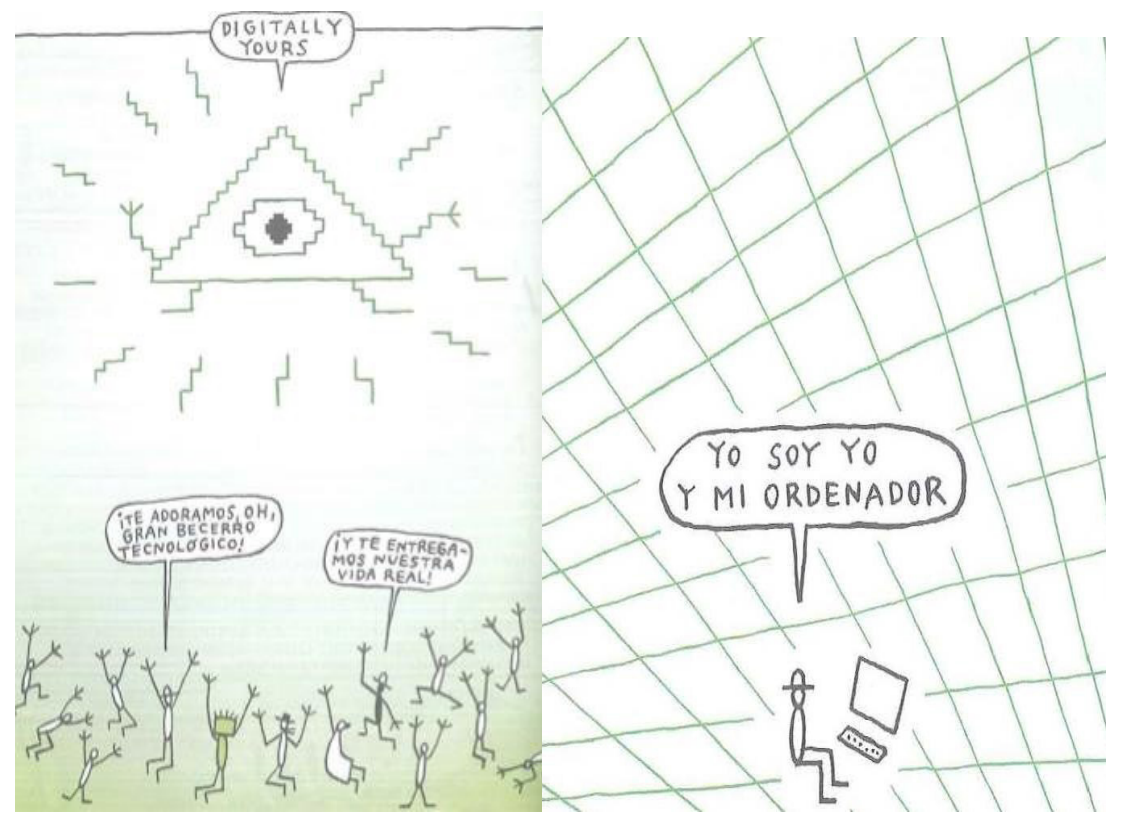

Fuente: Calpurnio. (2017)

Esta supeditación a lo digital está presente y afecta a muchas facetas de la vida de Cuttlas, como el empleo del tiempo, el autoconcepto o la identidad personal y las relaciones interpersonales. Sobre el deficiente empleo del tiempo, el autor bromea con la cuestión de la procrastinación, la conexión permanente para trabajo y ocio o la necesidad de actualizar las notificaciones y mensajes (Fig. 16 y 17) que nos ubican en un bucle estresante y adictivo.

Figura 16 y 17 - Calpurnio

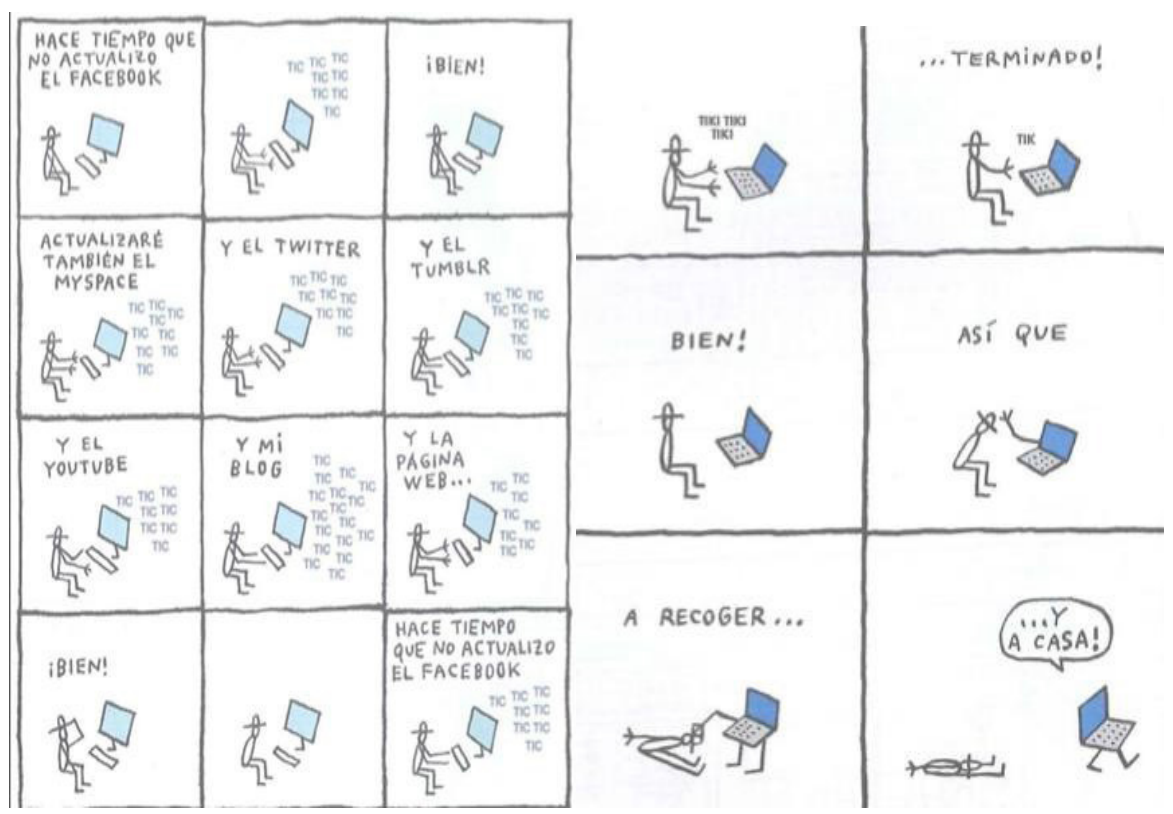

Fuente: Calpurnio. (2017) 
Ello hace explícita una de las consecuencias: la dependencia digital y la mala gestión del tiempo. Algo que, aun no estando diagnosticado clínicamente como adicción desde la Psiquiatría o la Psicología, es un problema con el que muchísimos lectores se sentirán identificados. Y derivada de estas prácticas se acaba en una supeditación excesiva de lo que hacemos a las tecnologías en los hábitos de ocio, trabajo y relaciones. La conclusión, al final, es que lo digital domina nuestra existencia (Fig. 18).

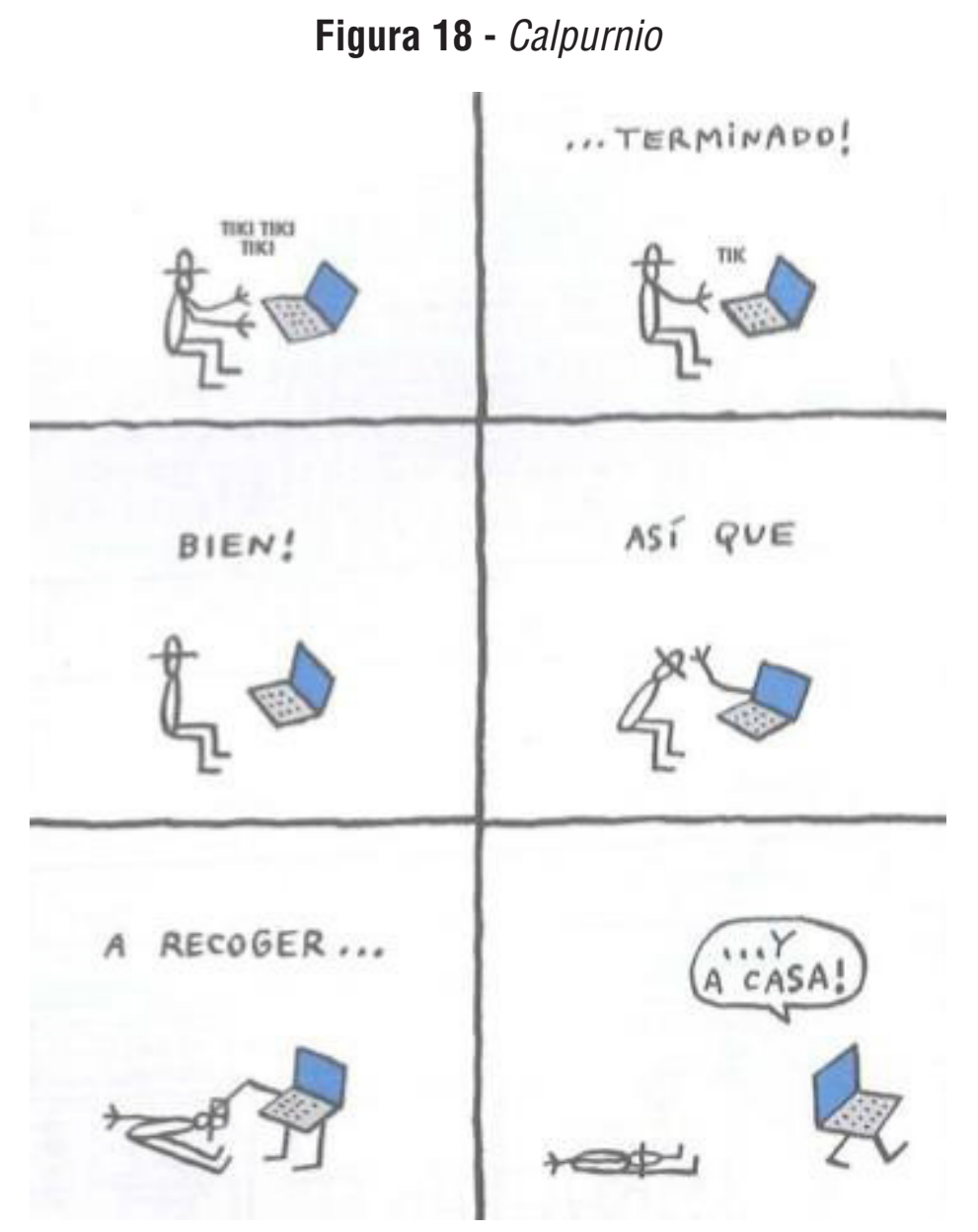

Fuente: Calpurnio. (2017)

Cuttlas está identificando en estas historietas una serie de factores que hacen adictivas las redes sociales y las aplicaciones que usamos en los dispositivos móviles (Figs. 19 y 20): en primer lugar, la motivación para acceder como una vía de obtener reconocimiento de los demás, a través de los "Me gusta", las peticiones de amistad, las repuestas y toda clase de interacciones. En segundo lugar, la facilidad de uso que anima a un estado de accesibilidad y conducta permanente. $Y$, en tercer lugar, las notificaciones push, que continuamente nos están llamando la atención para que nos reconectemos si es que nos habíamos "distraído" en cualquiera otra de las facetas de la vida. 
Figura 19 y 20 - Calpurnio

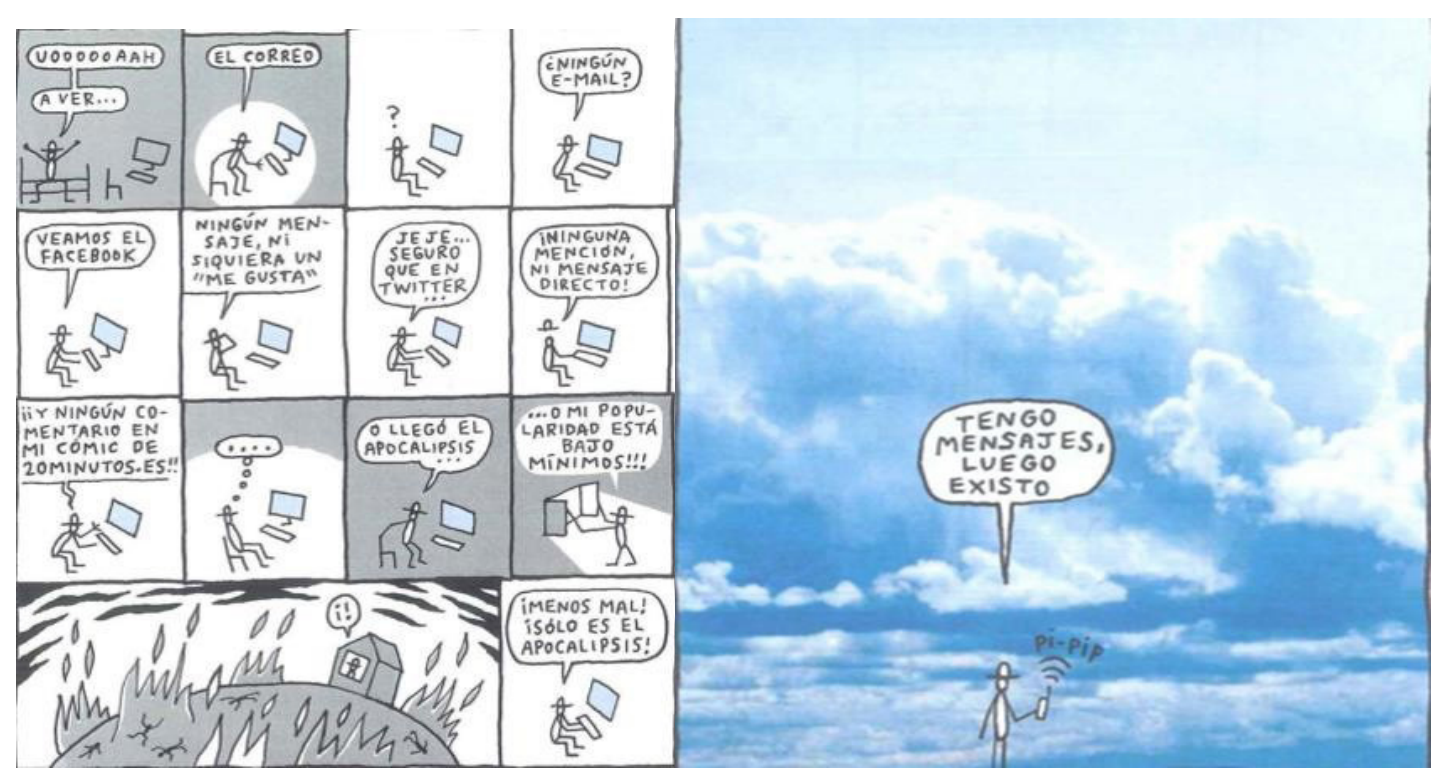

Fuente: Calpurnio. (2017)

Finalmente, dos repercusiones de gran relevancia personal y social son la vulnerabilidad a la manipulación, el empobrecimiento de las relaciones "cara a cara" y la falta la colaboración y comunicación con los demás si nos llevan al aislamiento (Figuras 21 y 22).

Figura 21 y 22 - Calpurnio (2017)

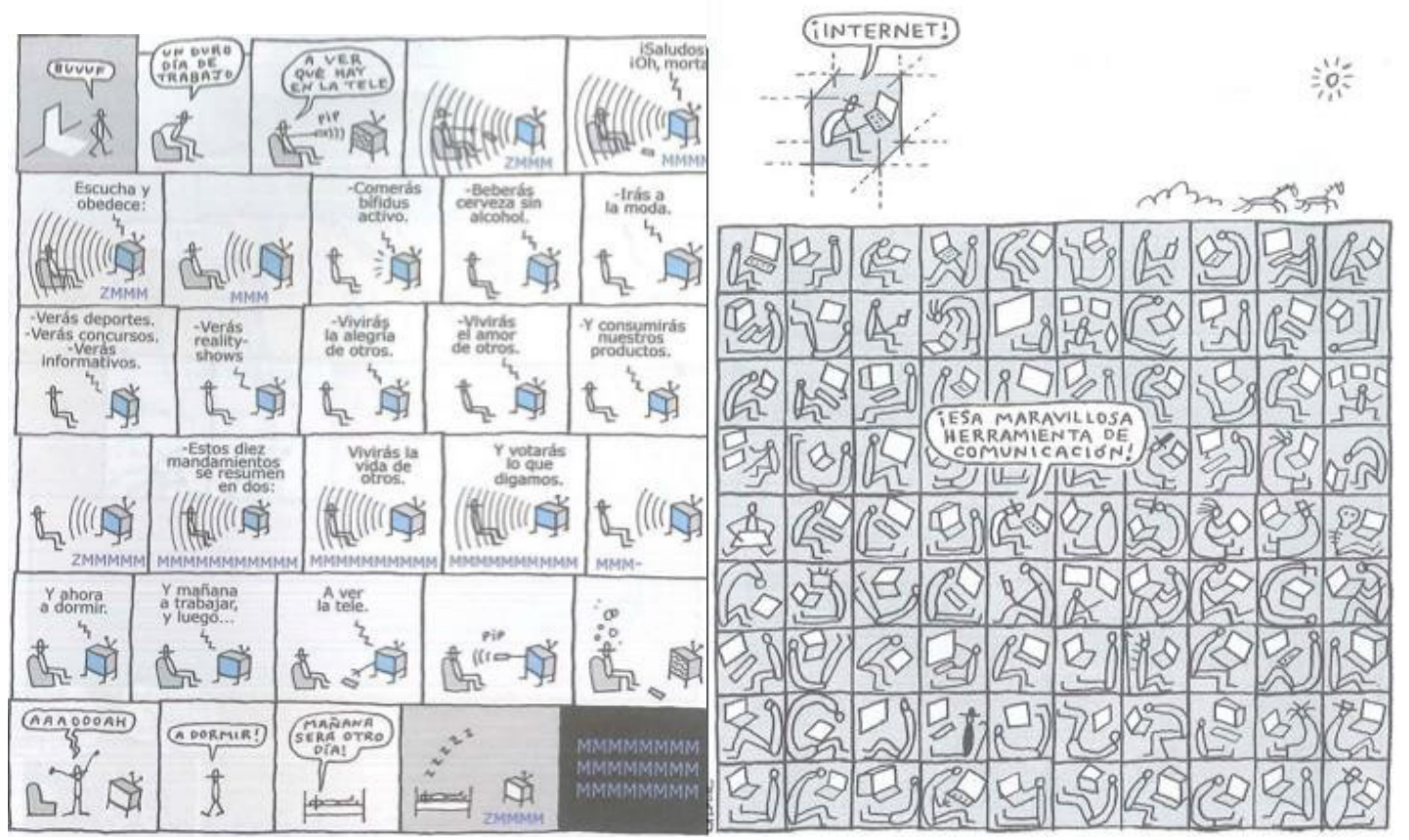

Fuente: Calpurnio. (2017) 


\section{ATRAPADOS EN LA RED $Y$ MANIPULADOS POLÍTICA Y SO- CIALMENTE: EL ROTO}

El Roto ha sido el referente fundamental de la sátira gráfica en España por su visión crítica, su capacidad de síntesis y su compromiso social, demostrado durante más de cuarenta años de presencia regular en los medios de prensa e Internet, pues no olvidemos que El País - donde sus viñetas se publican en español e inglés- tiene veintiún millones de visitantes únicos por mes. Sus dibujos tratan problemas controvertidos con los que influye en la opinión pública (FERNÁNDEZ; VILLAPLANA, 2016) como la crisis económica, la destrucción del medio ambiente, la manipulación política, la globalización, la precariedad, el nacionalismo o la tauromaquia. Son composiciones que contribuyen al pensamiento crítico sin tener que explicitar su visión: dejan al lector que haga su libre interpretación, por más que sea evidente su denuncia de la injusticia social, la desigualdad o el abuso de los poderes económicos y políticos, trasmitiendo una visión dramática y pesimista de la condición humana que ampara esas situaciones, revelando su estupidez.

En lo referido al mundo de la comunicación, El Roto ha dibujado muchas viñetas sobre la prensa escrita, la radio, la televisión, la publicidad, las tecnologías de la información y sus redes, reflejando casi siempre una mirada muy ácida sobre su capacidad de manipulación del sujeto. Esta es su primera enmienda a la totalidad: es una fuente de desinformación, no de conocimiento (Fig. 23).

Figura 23 - El Roto.

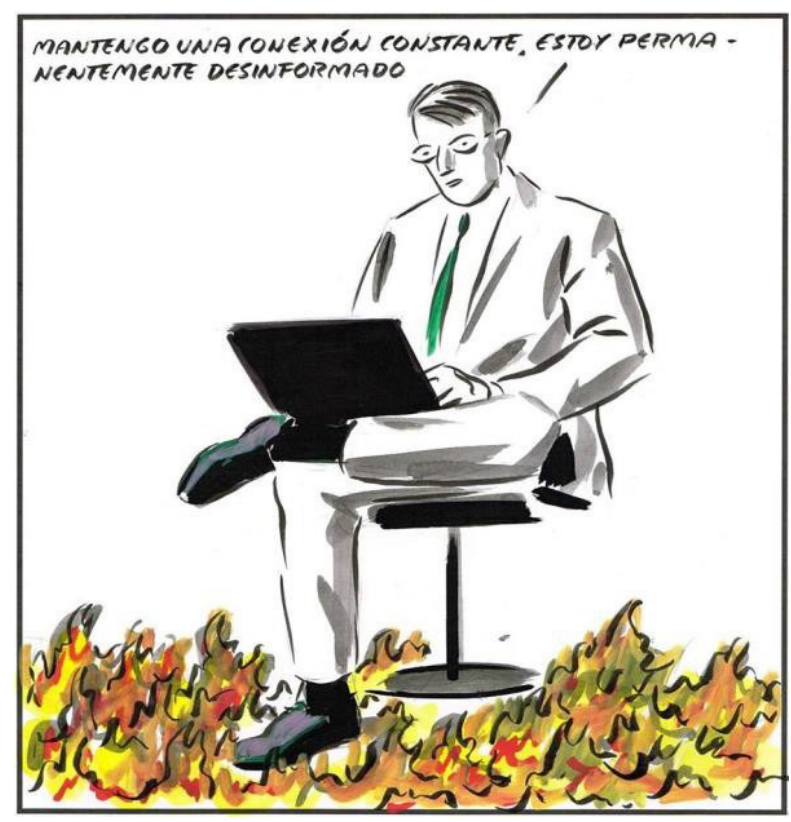

Fuente: El País, 16 de noviembre de 2018 
En segundo lugar, a este autor le preocupa la inconsciencia: negar o no ser conocedores de esos riesgos digitales nos deja indefensos. El Roto rechaza toda ingenuidad respecto a la apariencia de libertad, seguridad o facilidad de las redes, y defiende una actitud de sospecha como forma de prevención (Fig. 24 y 25).

Figura 24 y 25 - El Roto.
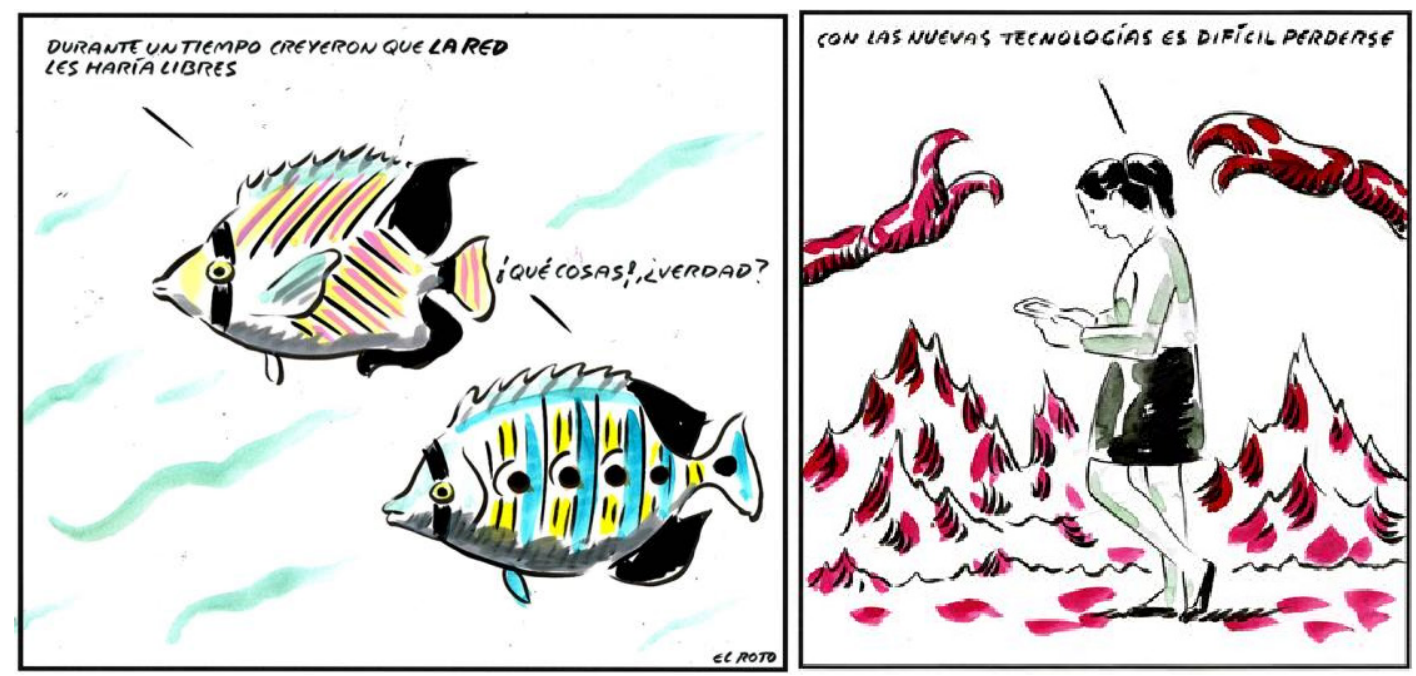

Fuente: El País, 27 de enero de 2017 y 5 abril 2019

Ya en su compendio de humor gráfico sobre el mundo de los Medios e Internet, titulado Camarón que se duerme (se lo lleva la corriente de opinión) Rábago (2012) venía a considerar la comunicación como un tsunami ruidoso que más que informar embota los sentidos: "cegados y ensordecidos por Ios medios, resulta necesario apartarse de esa corriente y echar una mano a aquellos que, arrastrados por las enloquecidas aguas, pidan ayuda". Y presentaba su labor "como un sistema de alarma" ante Internet: "La Red está en constante movimiento y uno nopuede fijar la atención. La gente piensa que está muy informada, pero es lo contrario. En realidad, no lo está porque no tiene tiempo para pensar y cuanto menos piense mejor para el poder": así respondía en El País con motivo de este libro (VICENT, 2012).

Y no estamos informados porque, en tercer lugar, lo que nos ofrecen las redes digitales es información o bien inconsistente, o malintencionada y falsa, que el autor no duda en considerar y dibujar como basura o excrementos. Para El Roto la gratuidad de la mayoría de contenidos de Internet facilita el engaño, y quizás contrapone a la prensa tradicional como fuente de información más contrastada respecto de la facilitad para publicar en Internet que puede hacer "todo el mundo". (Fig. 26 y 27 ). 
Figura 26 y 27 - El Roto.
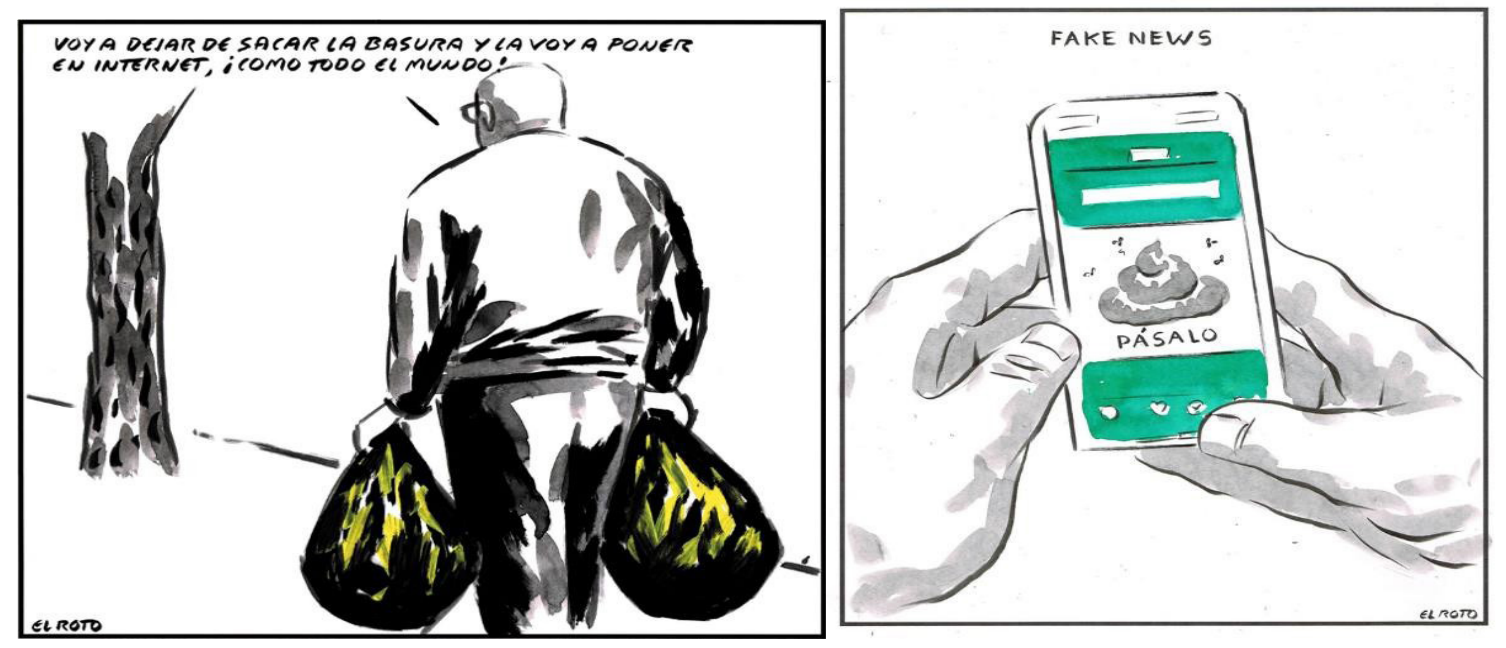

Fuente: El País, 11 de diciembre de 2017 y 3 marzo 2020

Además, para El Roto, tendemos de sobrevalorar el poder de la tecnología para recrear una realidad idealizada que nos obnubila, o llegamos a creer que lo que las redes sociales contienen es un reflejo fiel de la realidad (Fig. 28 y 29 ).

Figura 28 y 29 - El Roto

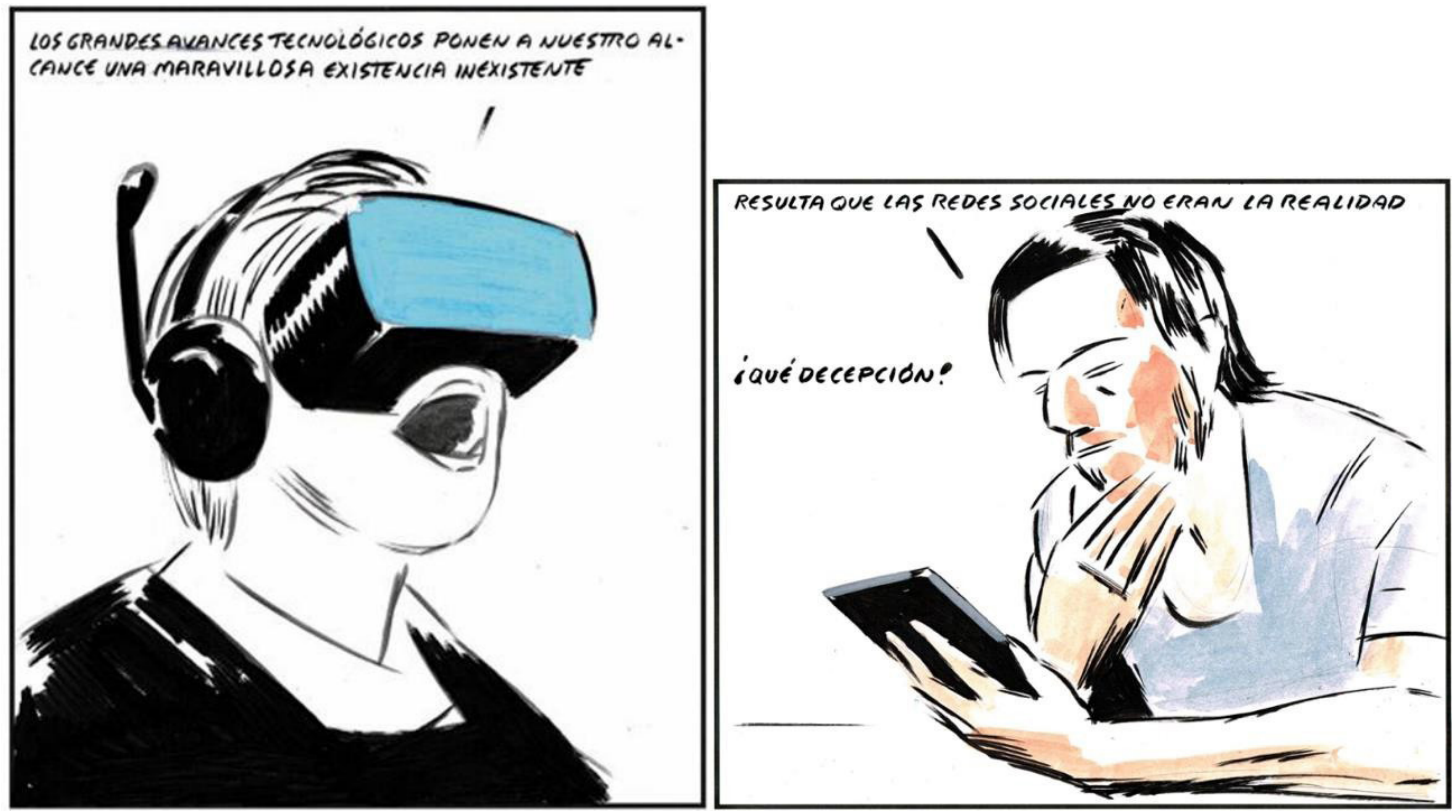

Fuente: El País, 8 de abril de 2015 y 29 junio 2016 
Un problema grave relacionado con ello es que nosotros mismos tendemos a idealizar nuestra situación y difundimos en las redes una versión deformada de nuestra identidad, pudiendo confundir a los demás 0 incluso a nosotros mismos (Fig. 30 y 31 ).

Figura 30 y 31 - El Roto
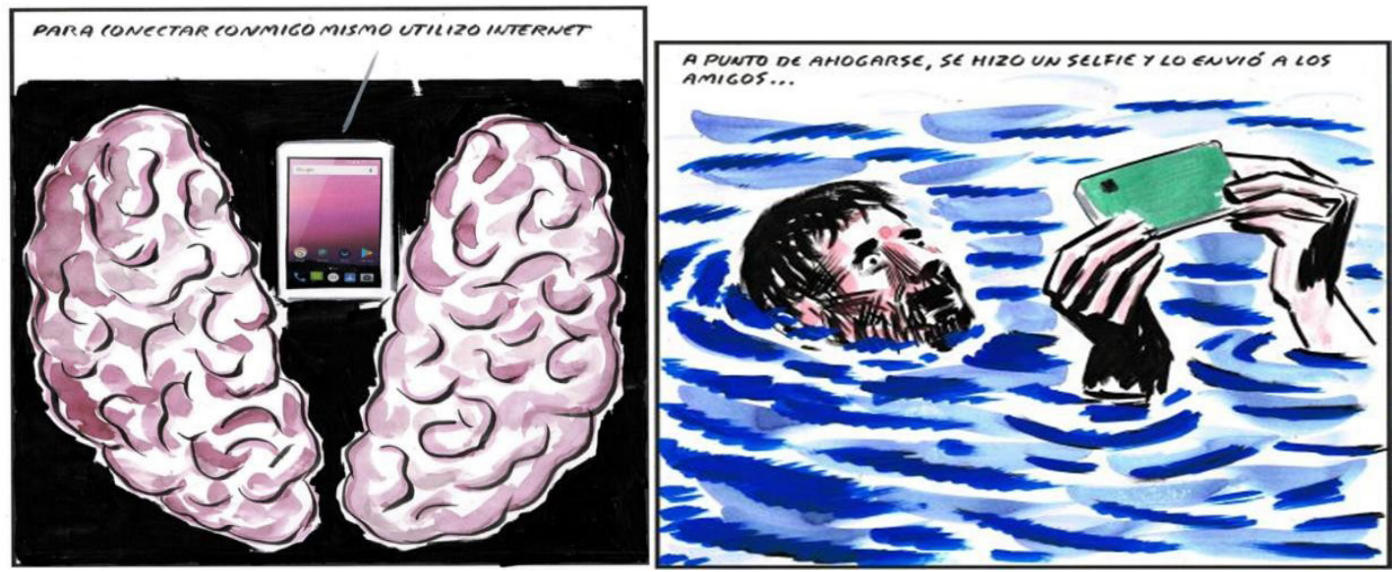

Fuente: El País, 19 de marzo de 2016 y 24 de enero de 2016

Para El Roto, el que esto ocurra no es fruto del azar, sino que los poderes económicosy políticos están interesados y nos inducen a utilizar las redes, a entregar datos personales y poder así abusar de los mismos para dominarnos o manipularnos (Fig. 32 y 33).

Figura 32 y 33 - El Roto
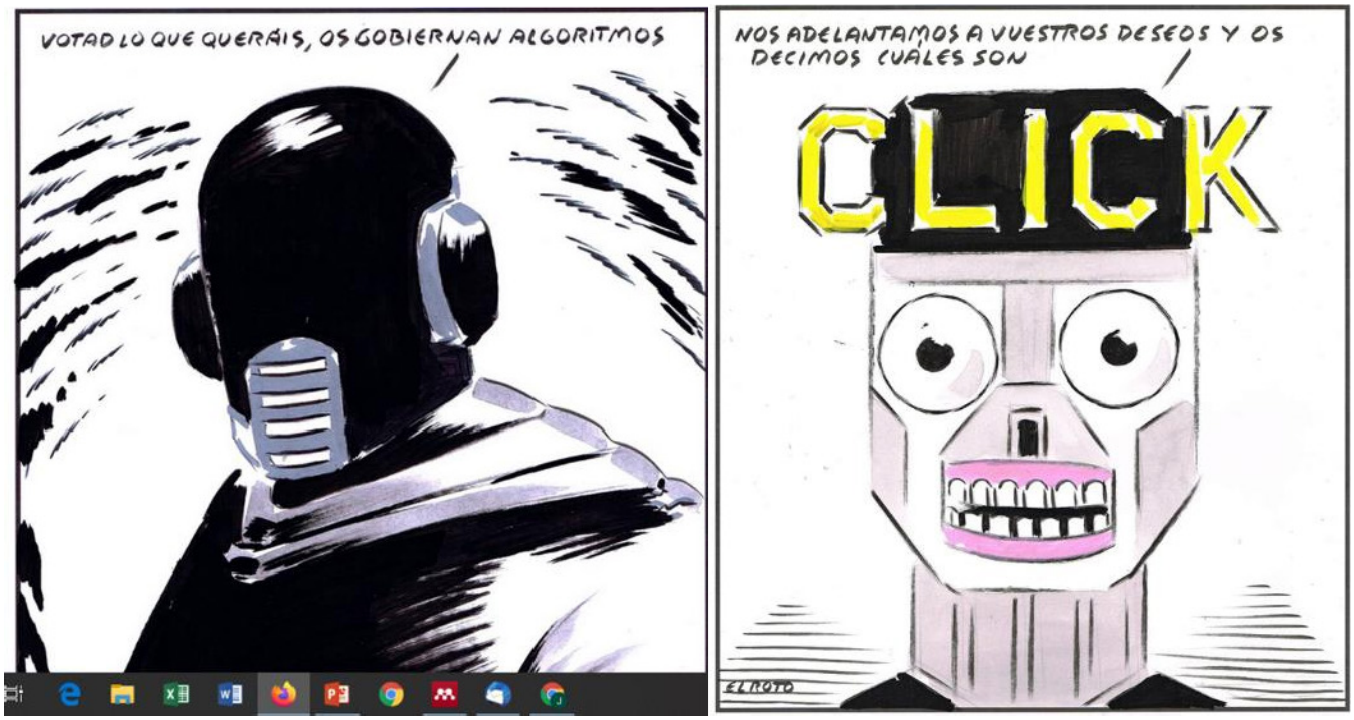

Fuente: El País, 19 de marzo de 2016 y 20 de diciembre de 2019

Pero es que, además, el que nos volquemos en la sociedad digital empobrece las relaciones personales 0 la solidaridad comunitaria (Fig. 34 y 35 ). 
Figura 34 y 35 - El Roto
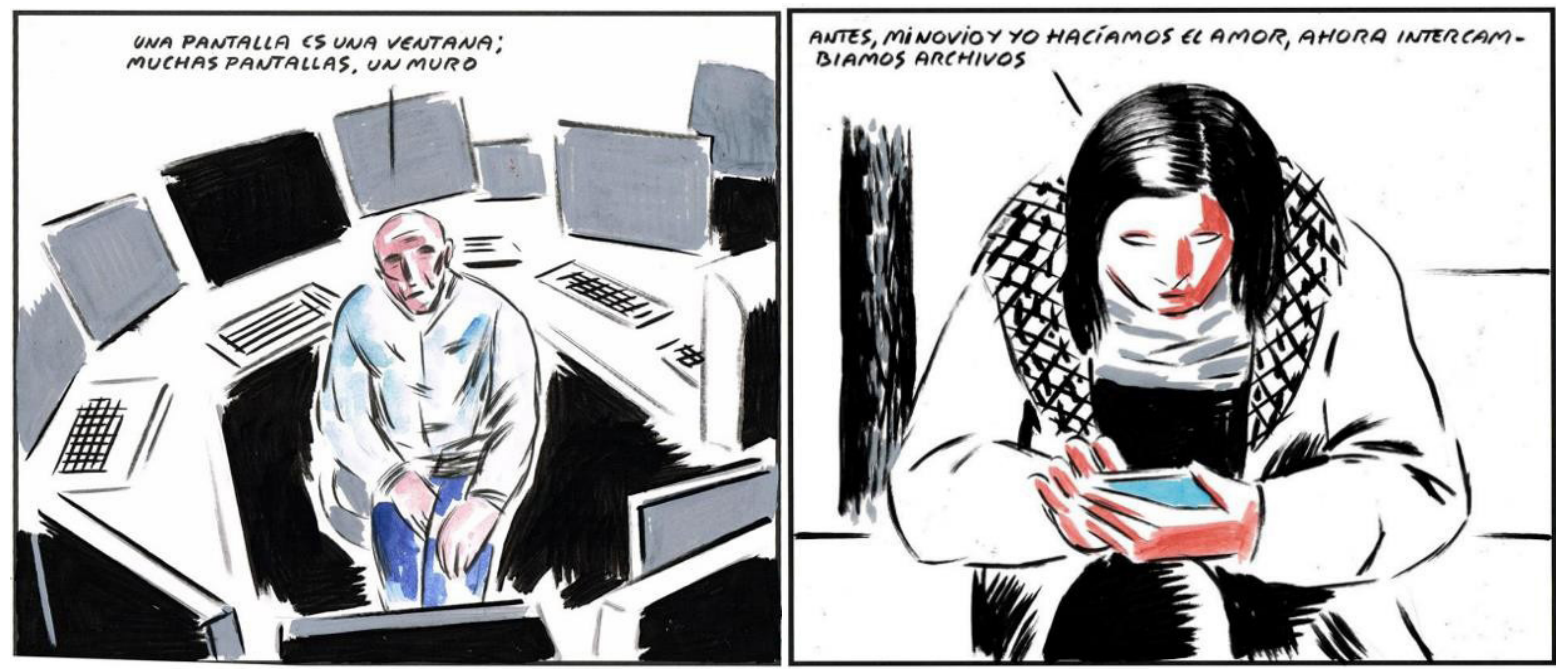

Fuente: El País, 2 de febrero de 2019 y 20 de diciembre de 2019

El Roto trata también sobre la situación de las próximas generaciones, y advierte de que la infancia y la juventud están siendo impregnadas de lo digital, a través de la educación escolar y familiar (Fig. 36 y 37 ).

Figura 36 y 37 - El Roto

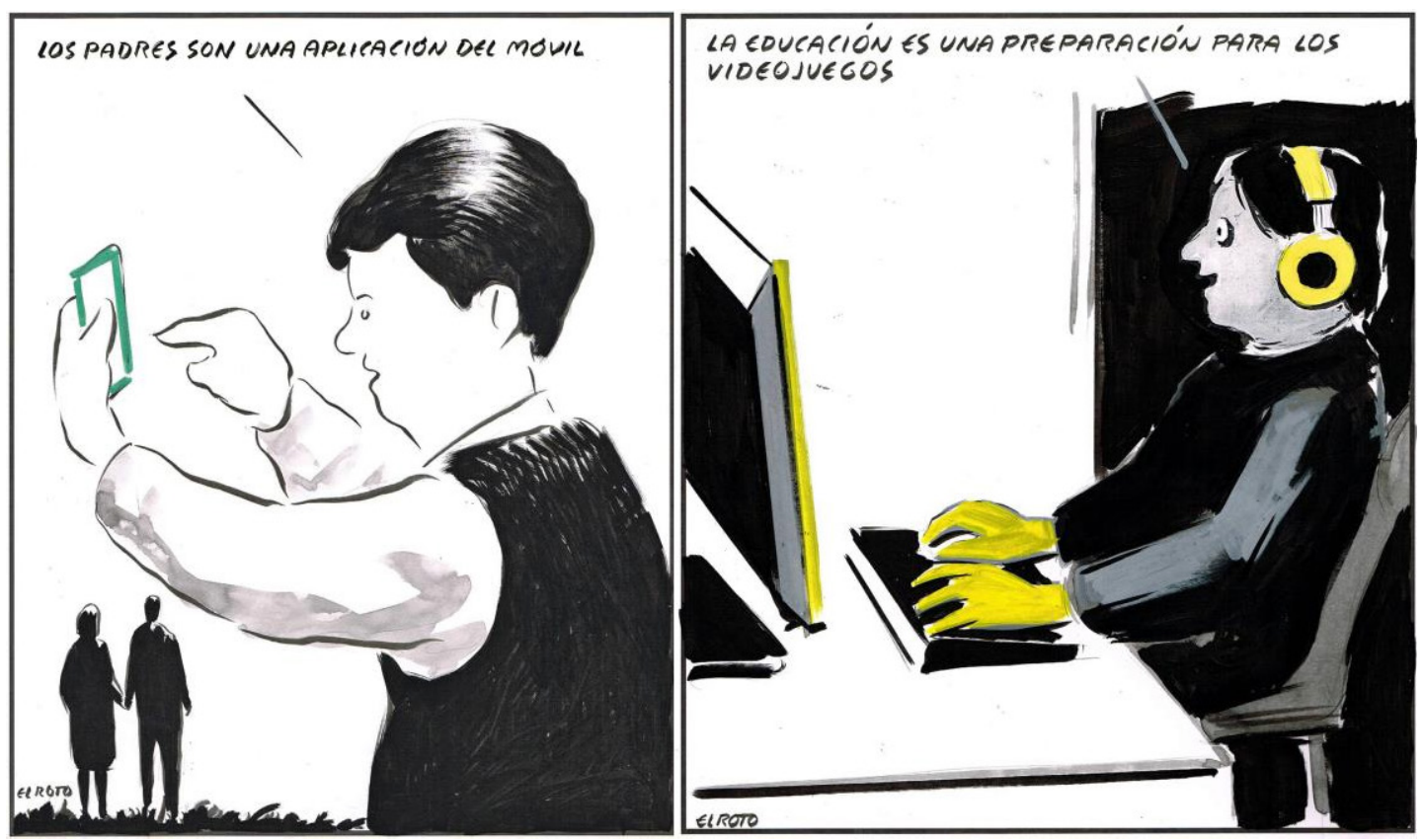

Fuente: El País, 5 de mayo de 2018 y 20 de octubre de 2018 
El Roto, en suma, considera imprescindible hacernos pensar críticamente sobre una sociedad digital que fortalece al poder porque lo sabe todo de nosotros, crea una verdad interesada, debilita 0 aísla al individuo y sumerge también en ese modelo a las nuevas generaciones (Fig. 38 y 39 ).

Figura 38 y 39 - El Roto

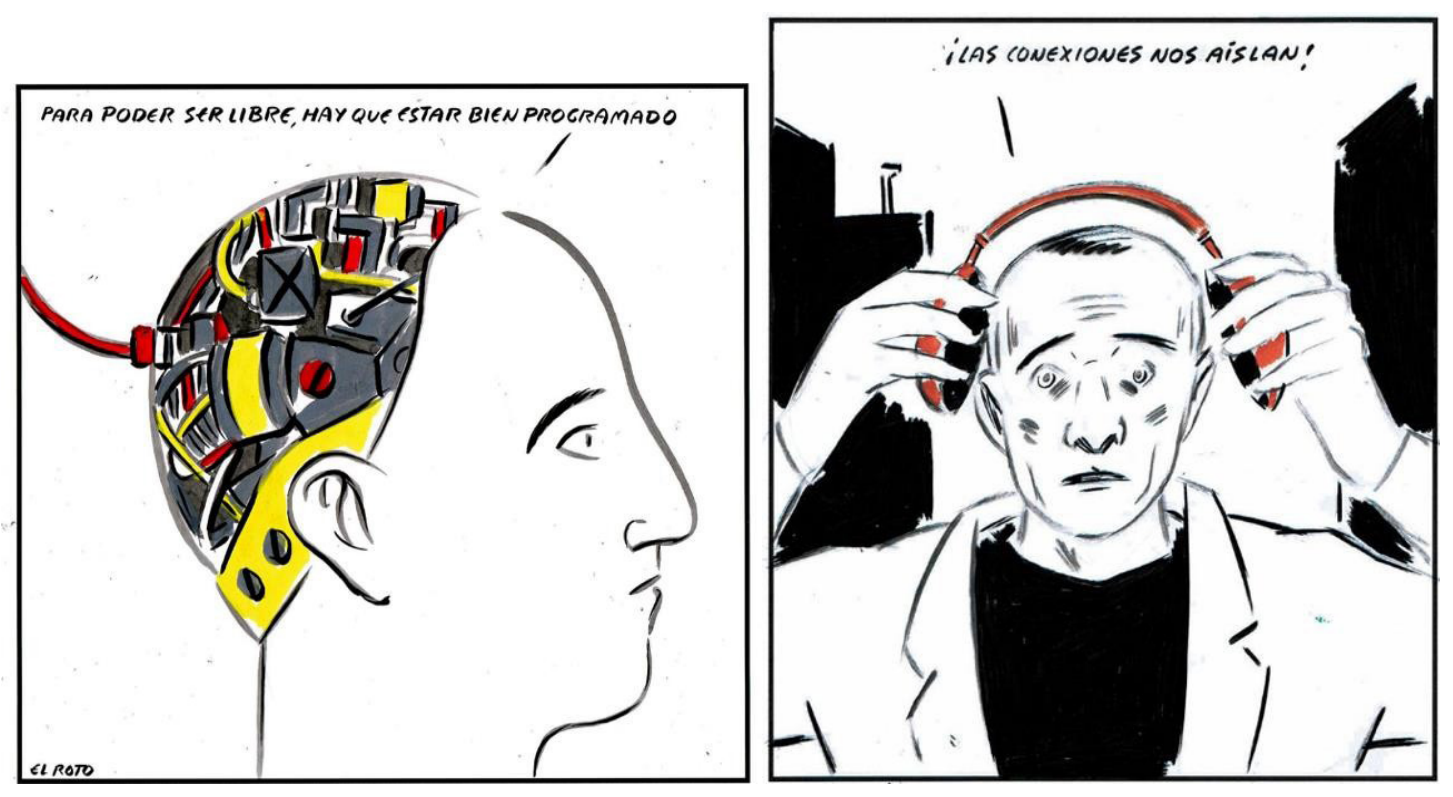

Fuente: El País, 9 de febrero de 2018 y 25 de marzo de 2015

\section{DISCUSIÓN}

Hemos pretendido mostrar cómo Calpurnio y El Roto usan la sátira gráfica para una crítica de la sociedad digital, por sus negativas repercusiones individuales y sociales. A lo largo de la revisión y descripción presentada se ha podido identificar que las viñetas de estos dos autores abordan riesgos 0 aspectos contraproducentes de la sociedad digital, como los que se sintetizan en la Tabla 1, y que tienen vínculos con las áreas del Marco Europeo de la Competencia Digital. 
Tabla 1: Críticas a la sociedad digital en Calpurnio y El Roto por áreas del DIGCOMP

\begin{tabular}{|c|c|}
\hline $\begin{array}{c}\text { Calpur- } \\
\text { nio }\end{array}$ & $\begin{array}{c}\text { El } \\
\text { Roto }\end{array}$ \\
\hline $\begin{array}{l}\text { 1. No tenemos alfabetizacióninformacional } \\
\text { y no sabemos organizar y gestionar los } \\
\text { contenidos personales que acaparamos } \\
\text { en el contexto digital (DIGCOMP 1 y 5) } \\
\text { 2. Hay inseguridad ante los posibles ataques } \\
\text { a nuestra información y a los disposi- } \\
\text { tivos ante la delincuencia digital (DIG- } \\
\text { COMP 4) } \\
\text { 3. El consumismo tecnológico exacerbado } \\
\text { nos lleva a renovar de forma constante } \\
\text { y acrítica los dispositivos tecnológicos } \\
\text { (DIGCOMP 4) }\end{array}$ & $\begin{array}{l}\text { 1. Internet y las redes sociales son una fuente } \\
\text { de desinformación, no de conocimiento } \\
\text { (DIGCOMP 1) } \\
\text { 2. Negar o no ser consciente de los riesgos } \\
\text { digitales deja indefensas a las personas } \\
\text { confiadas y la sociedad (DIGCOMP 4) } \\
\text { 3. Internet favorece la publicación y reproduc- } \\
\text { ción masiva de información irrelevante, ma- } \\
\text { lintencionada o falsa (DIGCOMP } 2 \text { y 3) } \\
\text { 4. Las personas idealizan el poder de las tec- } \\
\text { nologías y las redes para recrear una reali- } \\
\text { dad inexistente (DIGCOMP 4) }\end{array}$ \\
\hline $\begin{array}{l}\text { 4. Hacemos una valoración excesiva de lo } \\
\text { que supone la tecnología en nuestra vida } \\
\text { (DIGCOMP 4) } \\
\text { 5. La tecnología nos provoca un deficiente } \\
\text { empleo del tiempo: la procrastinación, } \\
\text { la conexión permanente, la necesidad de } \\
\text { actualizar las notificaciones y mensajes } \\
\text { conducen a un bucle estresante y adicti- } \\
\text { vo. (DIGCOMP 2, } 3 \text { y 4) }\end{array}$ & $\begin{array}{l}\text { 5. Las personas crean imágenes idealizadas y } \\
\text { deformadas de sí mismas creyendo que les } \\
\text { hará ser más reconocidas por los demás } \\
\text { (DIGCOMP } 2 \text { y 3) } \\
\text { 6. Las personas entregan sus datos privados, } \\
\text { y permiten que sean analizados por parte } \\
\text { del poder con fines políticos o económicos } \\
\text { (DIGCOMP 2, } 3 \text { y 4) }\end{array}$ \\
\hline $\begin{array}{l}\text { 6. Tenemos necesidad de acceder y usar } \\
\text { como una vía de obtener reconocimiento } \\
\text { de los demás (DIGCOMP 2, } 3 \text { y 4) }\end{array}$ & $\begin{array}{l}\text { 7. En la sociedad digitalizada se empobrecen } \\
\text { las relaciones personales y la solidaridad } \\
\text { comunitaria (DIGCOMP 2) }\end{array}$ \\
\hline $\begin{array}{l}\text { 7. Somos vulnerables a la manipulación con } \\
\text { fines políticos y económicos (DIGCOMP } \\
\text { 4) }\end{array}$ & $\begin{array}{l}\text { 8. La digitalización masiva fortalece al poder, } \\
\text { que sabe todo de nosotros, crea una verdad } \\
\text { interesada y debilita o aísla al individuo } \\
\text { (DIGCOMP 4) }\end{array}$ \\
\hline $\begin{array}{l}\text { 8. Existe el riesgo de empobrecer las rel- } \\
\text { aciones “cara a cara" y la colaboración } \\
\text { con los demás (DIGCOMP } 2 \text { y 4) }\end{array}$ & $\begin{array}{l}\text { 9. La Educación actual sumerge también a la } \\
\text { infancia en esa realidad digital omnímoda }\end{array}$ \\
\hline
\end{tabular}

Fuente: elaboración propia

Los riesgos digitales que señala Calpurnio son más fácilmente conectables con carencias específicas en las cinco áreas de la competencia digital, y tienen que ver en buena medida con aspectos de la vida diaria profesional, la comunicación o el ocio de las personas. De hecho, aunque su personaje no sea autobiográfico, sí que muchas de sus historietas sobre problemas digitales parecen aludir a 
su propia experiencia como dibujante y creador, que puede estar haciendo una autocrítica de su comportamiento digital.

Respecto a las denuncias implícitas en las viñetas de El Roto, aunque parten de situaciones y conductas que el autor observa en su entorno, plantean una crítica que tiene que ver mucho más con una interpretación política de la digitalización, en la que se deduce que ésta es instrumentalizada por el poder para la manipulación y el control de la ciudadanía, así como por los poderes financieros que pretenden determinar las formas de consumo y las relaciones humanas. Así vista, la sátira gráfica de El Roto lleva a pensar en la sociedad digital como una sociedad en que, más allá de los riesgos digitales de carácter instrumental o las destrezas que debemos adquirir, lo que debe preocuparnos es cómo la tecnología condiciona el conjunto de aspectos de la vida personal y social.

En cuanto a la valoración de las consecuencias de futuro implícitas de la sociedad digital para el individuo y el conjunto de la comunidad, vemos que los dos autores ofrecen matices diferentes: Mientras Calpurnio observa algunas posibilidades para el bienestar de las personas como herramientas que nos acompañan o nos acercan a la cultura o a los demás, El Roto más bien piensa que la situación es irreversible, que ya estamos atrapados. Quizás lo dibuje de forma tan explícita para prevenirnos, pero su diagnóstico, si nos atenemos a lo que se deduce de su obra, es francamente negativo (Fig. 40 y 41 ).

Figura 40 y 41 - Calpurnio (2017) y El Roto
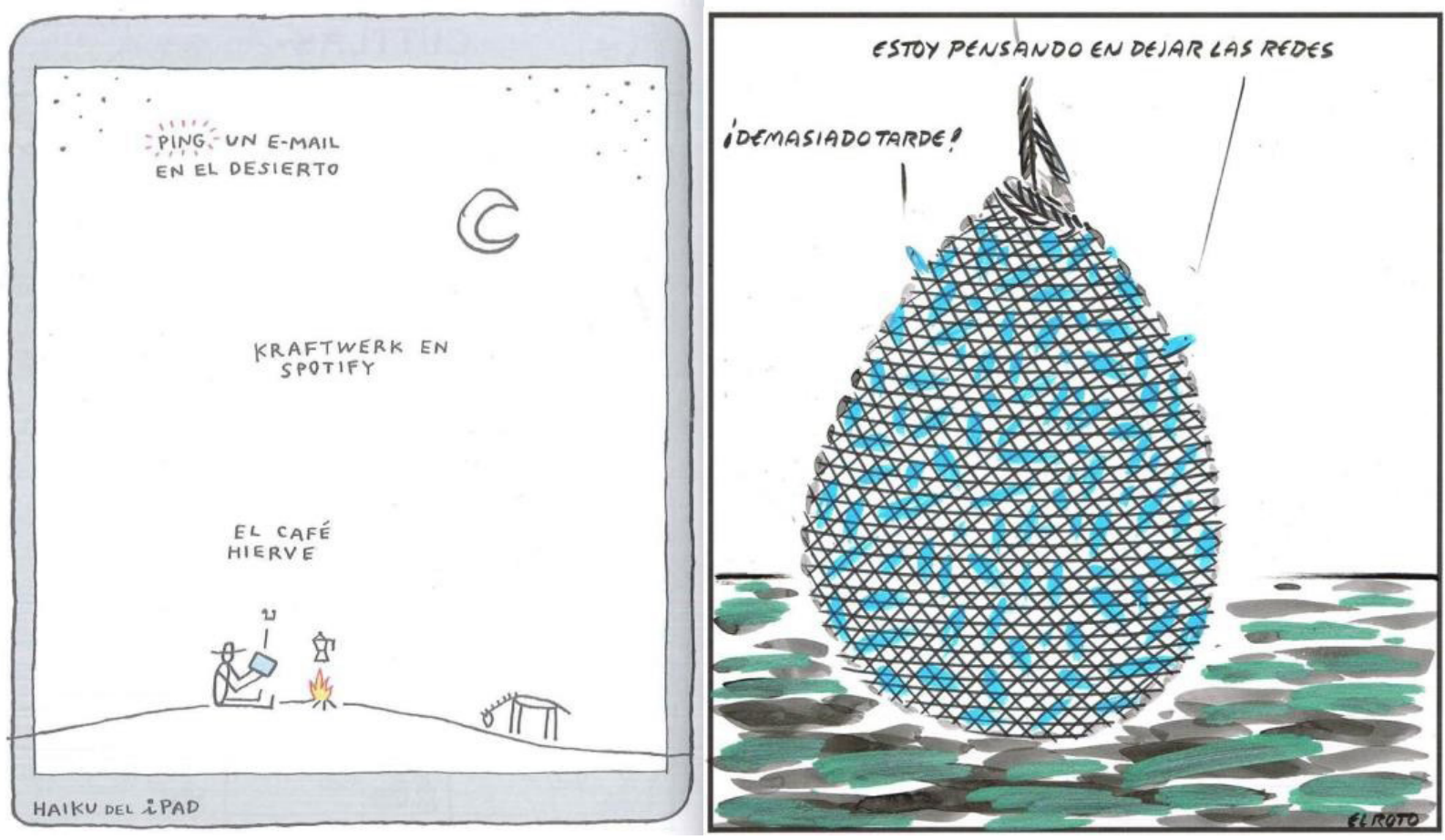

Fuente: Calpurnio (2017) y El País, 22 de enero de 2019 
Si analizamos el estilo, observamos que ambos autores coinciden en una búsqueda de la simplicidad y la expresión gráfica mínima, pero El Roto hace un desarrollo más definido y orgánico de los personajes. Lejos de la ingenuidad y el trazo casi infantil de Calpurnio, El Roto desarrolla la expresividad de los gestos, la tensión y la vida interior. Potencia en gran medida los contrastes de luz y sombra que envuelven la escena, y aplica el claroscuro o el dramatismo del color para destacar y dirigir la mirada. A diferencia de Calpurnio, más centrado en la narrativa y el diálogo, el trabajo de El Roto posee un carácter más pictórico en el que la iconicidad sí asume la tarea de anclar el mensaje verbal. Así, por ejemplo, sobre el problema de que creamos imágenes idealizadas y en parte falsas de nosotros mismos en el contexto digital, El roto es capaz de sintetizar la idea en una única imagen con un breve texto, mientras que Calpurnio describe el proceso e incluso la ironía que deduce de nuestra falsa identidad en las redes (fig. 42 y 43 ).

Figura 42 y 43 - El Roto y Calpurnio (2017)

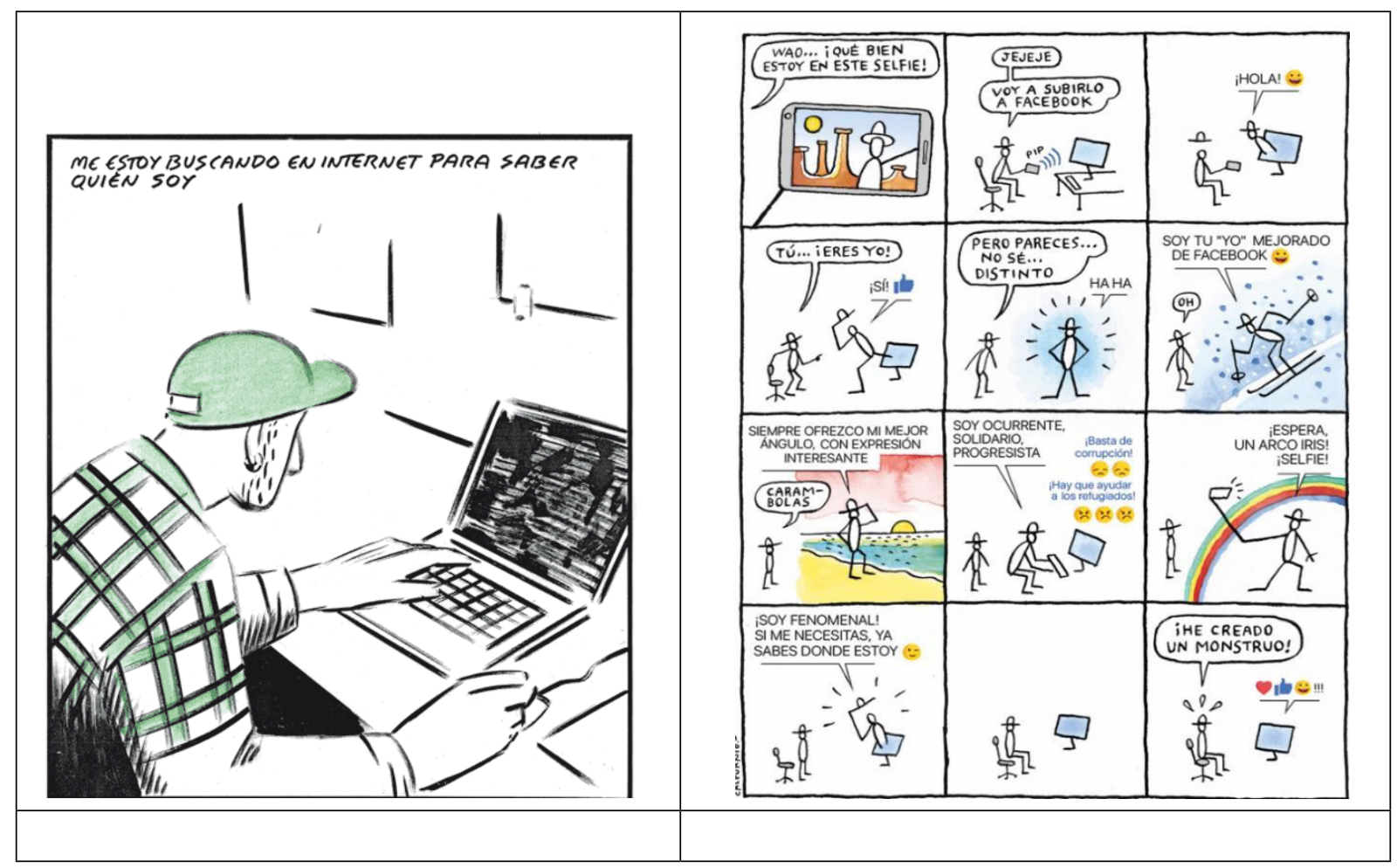

Fuente: El País, 7 de junio de 2011 y Calpurnio: Valencia Plaza 19 de mayo 2017

Ahora bien, ¿hasta qué punto son acertadas las alertas de estos autores?, ¿cómo puede afrontarse los problemas que suscitan? Lógicamente, no es su misión aportar soluciones; corresponde a las personas como responsables de su propio aprendizaje a lo largo de la vida y a las instituciones educativas 0 culturales como las bibliotecas Gómez-Hernández, 2002) trabajar para que seamos capaces de afrontar lo que implica la tecnología en la sociedad en su conjunto. 
En cierto modo, la sátira gráfica respalda las visiones de la alfabetización más holísticas, como las defendidas en la nueva conceptualización de CILIP y el modelo de meta- alfabetización de Jacobson \& Mackey, que la reconocen como una competencia evolutiva y crítica para el conjunto de facetas de la vida social, pretendiendo una alfabetización ciudadana (CUEVAS-CERVERO, MARQUES, PAIXÃO, 2014). La tecnología es vista desde su dimensión política, no como algo neutro, "solo" técnica, por Ios intereses a los que responde la promoción de su uso y por sus repercusiones, y en ese sentido es fundamental cuestionarla, comprenderla y usarla de forma muy reflexiva.

Un problema para la formación de la competencia digital crítica es que en cierto modo tiene un carácter "a contracorriente", porque transmite un mensaje crítico contra la inmediatez en la satisfacción de los deseos de información, cuestiona la validez de la que recibimos de los "amigos" o el excesivo predominio de la cultura de la imagen. Nos demanda un esfuerzo y una actitud de alerta que puede verse como reaccionaria o desfasada frente a tecnologías que consideramos naturales sin que nos inspiren sospecha. Como nos recuerda Rodríguez (2019:13) en su obra sobre el homo digitalis,

\begin{abstract}
"toda tecnología crea un entorno que percibimos como familiar y diáfano [...] porque el conjunto de artefactos, dispositivos y formatos que lo conforman constituyen parte natural de sus vidas, son mediaciones naturales entre cada uno de ellos y el exterior. Un nativo - digital, telegráfico, tipográfico, según las épocas- apenas puede dar cuenta de la falta de naturalidad de un artefacto más que cuando se estropea y revela su resistencia a seguir funcionando, cuando experimenta la tozuda fricción de un aparato que se resiste a prestar servicio, o cuando asiste al nacimiento e invención de una nueva tecnología que amenaza con desplazar la que usaba, conocía y daba por principal".
\end{abstract}

Es decir, hemos nacido con tecnologías en las que estamos inmersos de forma natural y en apariencia nos resuelven problemas, nos gratifican, nos relacionan con los demás, nos dan reconocimiento social y nos distraen. Así, cuesta cuestionar la calidad de la información que consumimos o el tiempo que nos roba; incluso siendo conscientes de los riesgos digitales por los datos y permisos que concedemos, en general somos incapaces de negarnos a cualquier petición de las aplicaciones móviles.

Por todo esto precisamente nos parece interesante lo que hacen los humoristas gráficos: abrirnos la perspectiva, acercándonos a una categorización de los riesgos digitales que, sin tener un carácter académico, acierta de pleno al mostrarnos desde el humor problemas que describen los teóricos desde la Psicología, la Sociología o las Ciencias de la Información y la Comunicación. La viñetas de El Roto o Calpurnio podrían acompañar e ilustrar obras como Datanomics, de Llaneza 
González (2019), en lo relativo al abuso de nuestros datos y los riesgos sobre la privacidad; El enemigo conoce el sistema, de Marta Peirano (2019) a propósito de cómo las aplicaciones y redes sociales se diseñan para mantenernos continuamente conectados hasta forzar conductas cercanas a la adicción; Abuso de Internet, de Echeburúa-Odriozola (2016), que explica usos problemáticos que podrían haber sido objeto de la sátira visual de los dibujantes aquí estudiados, o Gestión de información personal (FRANGANILLO, 2018) que enseña a organizar nuestros contenidos digitales.

En ese sentido, la obra de los humoristas puede facilitar la labor de las bibliotecas para una alfabetización informacional crítica, al ofrecerse al debate social y la opinión pública a través de Ios Medios de Comunicación, pudiendo usarse como una herramienta en programas que enseñen a practicar un uso reflexivo y crítico de los dispositivos, medios y vías

que se nos ofrecen. Se trata de:

\begin{abstract}
"potenciar en los procesos formativos de competencias informacionales una actitud de cuestionamiento de las propias prácticas, para ayudar a una asimilación inteligente y un buen aprovechamiento. Sin un pensamiento crítico el exceso de innovaciones, posibilidades, tecnologías y servicios nos llevarán al agobio, la saturación, la desorientación o la pérdida del sentido de nuestro comportamiento informacional” (Gómez-Hernández, 2012: 207).
\end{abstract}

Una cuestión relevante que puede abordarse desde el humor es el preocupante conformismo sobre la información proporcionada por Google y otros buscadores, que consumimos al modo de la “comida basura" tan solo porque nos parece atractiva y es inmediata, accesible y económica. El fenómeno de la desinformación, la aceptación de noticias falsas (NEVES; BORGES, 2020) o la recepción y redifusión de información irrelevante nos va conduciendo a una vulnerabilidad evidente, como hemos visto en los dibujos de Calpurnio y El Roto. Frente a ello se debe contribuir a que la ciudadanía desarrolle criterios propios, alimentándose de una slow information como propone Urbano (2018) al modo delmovimiento slow food. Se trata de aprender a hacernos buenas preguntas respecto a nuestras necesidades, para encontrar la información más significativa de las fuentes idóneas, y saber aprovecharla y asimilarla, en lugar de conformarnos con esos contenidos que nos llegan aleatoria o interesadamente desde las redes sociales como un "flujo continuo que de forma creciente recibimos en modo push mediante alertas". Para ello tenemos que generar en las personas la motivación y la voluntad de dedicar y disfrutar el tiempo necesario ejercitando su mente - sugiere Urbano- más allá de la inmediatez de las respuestas de Google basadas en el historial de búsqueda o las recomendaciones sociales que acaparan nuestro tiempo de lectura. 
Igualmente, otra cuestión sobre la que pensar a través de las viñetas satíricas podría ser la de la gestión del tiempo conectados, para integrarla dentro de la competencia informacional (Gómez-Hernández, 2013). El fin sería prevenir o afrontar la fatiga 0 tecnoestrés digital y la pérdida de atención vinculada a la marea informativa en que nos desenvolvemos, y que puede conducir a la incapacidad de tomar decisiones, a la superficialidad y otros desequilibrios. Pues, en expresión de Ortoll \& Cobarsí-Morales (2016), "un uso desmedido y compulsivo de la conexión digital puede afectar nuestro desempeño profesional, o ser obstáculo para una armoniosa vida personal, familiar y social".

\section{REFLEXIONES FINALES}

Creemos que las imágenes de los autores estudiados tienen gran fuerza para golpear al lector y ayudarle a reaccionar. Cuestionan la sociedad digital, su influencia en nuestras conductas privadas y públicas, y los aspectos políticos y económicos involucrados, que pueden tener consecuencias indeseadas como el sometimiento o la manipulación de las personas (Fig. 44 y 45).

Figura 44 y 45 - El Roto

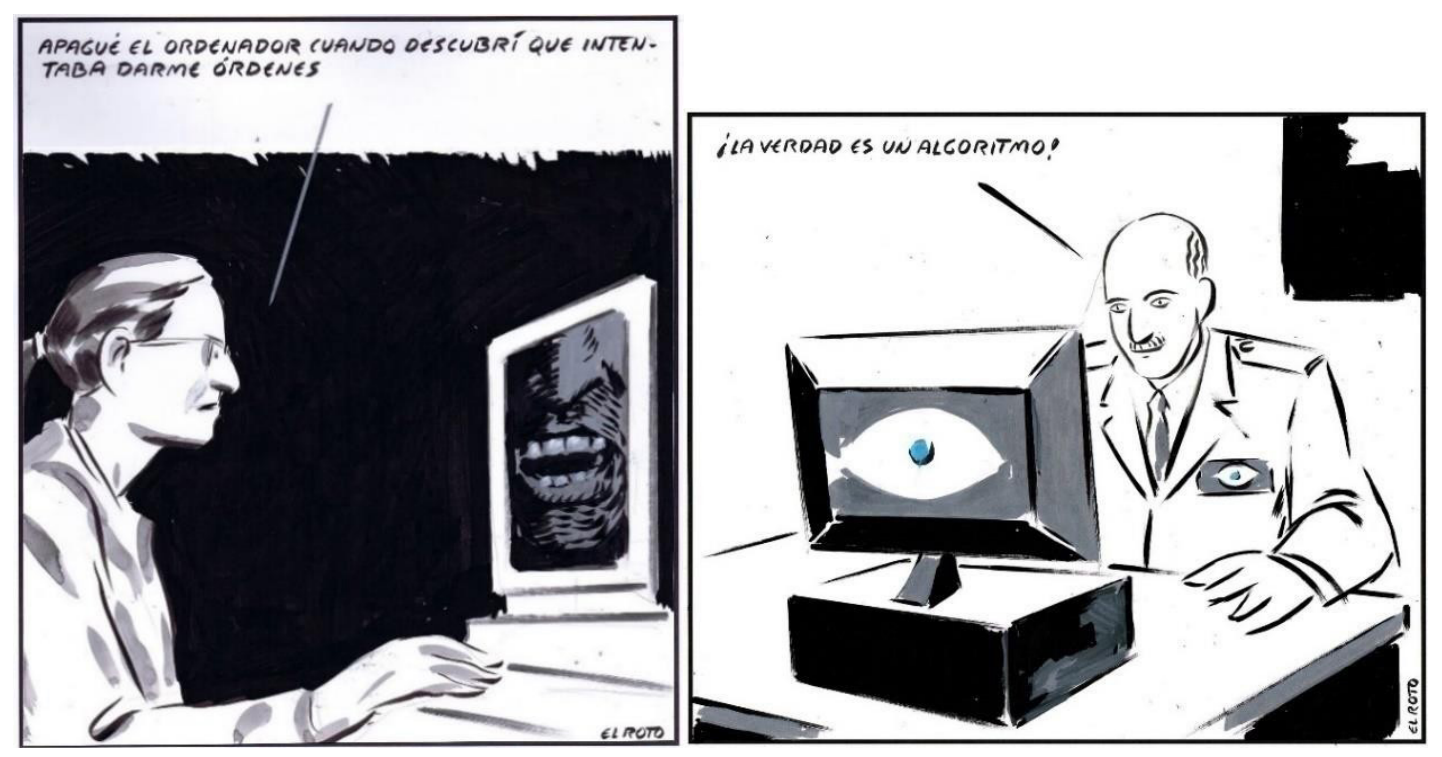

Fuente: El País, 11 de enero de 2019 y 5 de mayo de 2017

Es evidente que nuestra inmersión digital es creciente y muy probablemente irreversible; durante 2020, especialmente, el confinamiento por la pandemia Covid-19 nos ha hecho más dependientes de 
la tecnología, en la que nos hemos apoyado para poder seguir trabajando, comprando, enseñando y aprendiendo, manteniendo la comunicación visual y emocional con la familia y las amistades, 0 entreteniéndonos con la música o lectura (Fig. 46).

\title{
Figura 46 - John Holcroft.
}

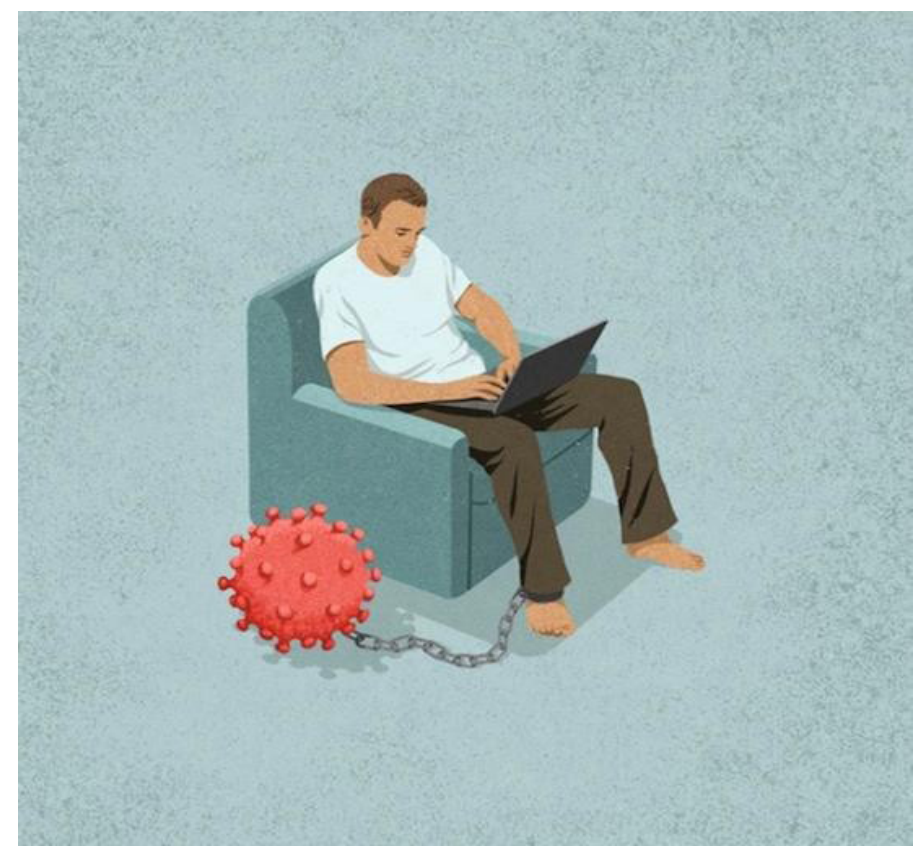

Fuente: http://www.johnholcroft.com/

Y, además, parece avecinarse también que la tecnología, a través de las aplicaciones de geolocalización y la inteligencia artificial, va a controlar la movilidad ciudadana, generando nuevos recelos que estarán justificados si no se garantiza la debida transparencia en el uso y la protección de la privacidad. Por tanto, la sátira gráfica sobre la sociedad digital sigue teniendo su espacio para mostrar una incómoda pero necesaria realidad, que puede contribuir a un más sano equilibrio en nuestras prácticas digitales.

Como señala Joaquín Rodríguez (2019: 471)

\begin{abstract}
"somos todavía primitivos de una nueva era que no acertamos a comprender y no cabe hacer otra cosa que problematizar cualquier supuesta evidencia para tener la mínima oportunidad de conducimos racionalmente, para superar conscientemente las incertidumbres de nuestra evolución hacia una nueva condición, la de homo digitalis".
\end{abstract}

En tanto homo digitalis la meta personal es aprender a discernir cómo conducirnos con inteligencia para -concluye Rodríguez- saber rechazar lo que fomente apegos automáticos o espejismos irreflexivos, escapando de nuestro control por intereses ajenos y maliciosos. Pero a la vez, 


\begin{abstract}
"aceptar aquello que nos empodere y nos enriquezca, aquello que nos libere y nos haga crecer; aquello que contribuya a que cada cual pueda trazar con claridad, mediante el escrutinio y la deliberación, su destino personal [...]; aquello, en fin, que nos ayude a deliberar de la manera más consciente posible y con el mayor conocimiento histórico que esté a nuestro alcance para tomar decisiones fundamentadas sobre nuestro futuro, indeleblemente unido al de la tecnología" (RODRÍGUEZ, 2019: 470-471).
\end{abstract}

Pues bien: la sátira digital nos obliga a reírnos de nosotros mismos al vernos reflejados y nos hace evidentes a través del humor comportamientos paradójicos. Por ello la consideramos una mirada lúcida y útil para una deliberación más consciente sobre los riesgos digitales y los hábitos que debemos adoptar, cambiar o mejorar. El humor gráfico puede ayudar a formar sujetos que logren autodeterminar de forma equilibrada su relación con lo informativo-digital.

\title{
REFERENCIAS
}

BARRERO, M. Derivas de la sátira gráfica en el siglo XXI. RBA contra El Jueves, 2014. Tebeosfera. Disponibel em: https://www.tebeosfera.com/

BAUMAN, Z. Liquid times: living in an age of uncertainty. Polity Press, 2007. BERROCAL, S.; CAMPOS-DOMÍNGUEZ, E.; REDONDO, M. Media prosumers in political communication: Politainment on YouTube. Comunicar, v. 22, n. 43, 2014.

CILIP. Cilip definition of information literacy 2018. Traducción al castellano: Sales, Dora. "Definición de alfabetización informacional de Cilip, 2018”. Anales de Documentación, v.1, n. 23, 2020. Disponibel em: https://doi.org/10.6018/analesdoc.373811

CUEVAS-CERVERO, A.; MARQUES, M.; PAIXÃO, P. B. S. A alfabetização que necessitamos: informação e comunicação para a cidadania. Informação \& Sociedade: Estudos, v. 24, n. 2, 2014. Disponibel em: https://periodicos.ufpb.br/ojs/index.php/ies/article/view/16619

ECHEBURÚA-ODRIOZOLA, E. Abuso de Internet. Madrid: Pirámide, 2016. ECO, U. Apocalípticos e integrados. Barcelona: Lumen, 1965.

FERNÁNDEZ TOLEDO, P.; VILLAPLANA RUIZ, V. El Roto and graphic humour as a generator of alternative public opinion in Spain. In: Anti-Austerity and Media Activism series, 2016. Disponibel em: https://www.opendemocracy.net/uk/austerity-media/piedad-fern- ndez-toledo-virginia-villaplanaruiz/el-roto-and-graphic-humour-as-ge

FERRARI, A. Digcomp: A framework for developing and understanding digital competence in Europe. In: PUNIE, Y. \& BRECKO, B. N. JCR Scientific and Policy Reports, 2013. Disponibel em: https://doi. org/10.2788/52966

FRANGANILLO, J. Gestión de información personal: integración mediante el correo electrónico. Barcelona: UOC, 2018. 
GÓMEZ-HERNÁNDEZ, J-A. La alfabetización informacional como servicio de las bibliotecas. Referencias, 2, 2002. Disponibel em: http://eprints.rclis.org/28510/

GÓMEZ-HERNÁNDEZ, J.-A. Alfabetización y autocrítica del comportamiento informacional mediante el humor gráfico de El Roto y Mauro Entrialgo. Anuario ThinkEPI, v. 6, 207-212, 2012. Disponibel em: http://eprints.rclis.org/16917/1/207-212-I4-Alfabet-y- autocritica-humor-grafico-JA-Gomez-1.pdf

GÓMEZ-HERNÁNDEZ, J.-A. La gestión del tiempo como dimensión de la competencia informacional. Anuario ThinkEPI, v. 7, 28-36, 2013. Disponibel em: http://eprints.rclis.org/19421/1/028-036-GomezGestion-tiempo.pdf

GONZALEZ-GARCÍA, E., \& CHACÓN-LÓPEZ, H. Las ilustraciones de Pawel Kuczinsky como recurso educativo y crítica social. Dedica. Revista de Educação e Humanidades, n. 14, 2018. Disponibel em: https://doi.org/10.30827/dreh.v0i14.7478

GUBERN, R. (1972). El Lenguaje de Ios comics. Barcelona: Península, 1972.

JACOBSON, T. E., \& MACKEY, T. P. Proposing a metaliteracy model to redefine Information Literacy. Communications in Information Literacy, v. 7, n. 2, 2013.

LLANEZA GONZÁLEZ, P. Datanomics : todos los datos personales que das sin darte cuenta y todo Io que las empresas hacen con ellos. Bilbao: Deusto, 2019.

MARTIGNONE, H., \& PRUNES, M. Historietas a diario: Ias tiras cómicas argentinas de Mafalda a nuestros días. Buenos Aires: Libraria, 2008.

MCCLOUD, S. Entender el cómic: el arte invisible. Bilbao: Astiberri, 2007.

MELÉNDEZ MALAVÉ, N. El humor gráfico en el diario “El País” durante la transición política española (1976-1978). Málaga: Universidad de Málaga, 2005.

NEVES, B. C., \& BORGES, J. Por que as Fake News têm espaço nas mídias sociais? Informação \& Sociedade: Estudos, v. 30, n. 2, 2020. Disponibel em: https://doi.org/10.22478/UFPB.18094783.2020V30N2.50410

ORTOLL, E., \& COBARSÍ-MORALES, 0. Conexión y desconexión digital: una reflexión.

Anuario ThinkEPI, v.10. 165-171. Disponibel em: https://doi.org/10.3145/thinkepi.2016.33

PEIRANO, M. El enemigo conoce el sistema. Manipulación de ideas, personas e influencias después de la economía de la atención. Madrid: Penguin Random House, 2019.

PEÑAMARÍN, C. El humor gráfico del franquismo y la formación de un territorio translocal de identidad democrática. Cuadernos de Información y Comunicación, v. 7, 351-380, 2002.

PITRI, E. Children's funny art and the form it can take over time. International Journal of Education Through Art, 7(1), 81-96, 2011. Disponibel em: https://doi.org/10.1386/eta.7.1.81_1 
RODRÍGUEZ, J. Primitivos de una nueva era : cómo nos hemos convertido en "Homo digitalis". Barcelona: Tusquets, 2019.

URBANO, C. Sobre la autodeterminación del usuario de información en tiempos de acceso social a los contenidos digitales. Anuario ThinkEPI, v. 12, 236-241, 2018. Disponibel em: https://doi. org/10.3145/thinkepi.2018.35

VICENT, M. Lo que está en Internet no deja rastro. Entrevista a El Roto. El País, 2012.

VODAFONE. Comunica con humor. Una espectacular y única selección de viñetas cómicas dedicadas al móvil. Madrid: Random House Mondadori, 2007.

\section{PUBLICACIONES DE LOS DIBUJANTES CITADOS}

Brieva. M. (2017). La gran aventura humana. Pasado, presente y futuro del mono desnudo. Barcelona: Reservoir Books.

Calpurnio (2017) Cuttlas. Barcelona: Debolsillo.

Eneko (2006). Mentiras, medias verdades, cuartos de verdad. Madrid: Sins Entido. Entrialgo, M. (2015). Interneteo y Aparatuquis. Madrid: Diábolo Ediciones.

Flavita Banana (2017). Archivos cósmicos. Bilbao: Astiberri.

Flavita Banana (2019). Archivos estelares. Bilbao: Astiberri.

Rábago, A. (2012) Caracol que se duerme (se lo lleva la corriente de opinión). Barcelona: Reservoirs books.

Rábago, A. (2019). No se puede mirar y otras estampas. Barcelona: Reservoir Books.

\section{TEXTO EN ESPAÑOL, PORTUGUÉS E INGLÉS DE LAS VIÑETAS CITADAS DE EL ROTO}

Fig. 23. El Roto, El País, 16 de noviembre de 2018 - Mantengo una conexión constante, estoy permanentemente conectado - I am constantly connected, I am permanently misinformed - Eu mantenho uma conexão constante, estou permanentemente desinformado

Fig. 24. El Roto, El País, 27 de enero de 2017 - Durante un tiempo creyeron que la Red les haría libres. Qué cosas ¿verdad? - For a time they believed that the Network would set them free. What things right?- Por um tempo eles acreditaram que a Rede os libertaria... Que coisas, certo?

Fig. 25. El Roto, El País, 5 abril 2019 - Con las nuevas tecnologías es difícil perderse - It's hard to get lost with new technology - Com as novas tecnologias, é difícil se perder 
Fig. 26. El Roto, El País, 11 de diciembre de 2017 - Voy a dejar de sacar la basura y la voy a poner en Internet, jcomo todo el mundo! - I will stop taking out the trash and put it on the Internet like everyone else - Vou parar de tirar o lixo e colocá-lo na Internet como todo mundo

Fig. 27. El Roto, El País, 3 marzo de 2020 - Fake news

Fig. 28. El Roto, El País, 8 de abril de 2015 - Los grandes avances tecnológicos ponen a nuestro alcance una maravillosa existencia inexistente - The great technological advances put within our reach a wonderful non-existent existence - Os grandes avanços tecnológicos colocam ao nosso alcance uma maravilhosa existência inexistente

Fig. 29. El Roto, El País, 29 junio de 2016 - Resulta que las Redes Sociales no eran la realidad. ¡Qué decepción! - It turns out that Social Networks were not reality. What a disappointment! - Acontece que as redes sociais não eram a realidade. Que decepção!

Fig. 30. El Roto, El País, 19 de marzo de 2016 - Para conectar conmigo mismo utilizo Internet I use the internet to connect with myself - Eu uso a internet para me conectar

Fig. 31. El Roto, El País, 24 de enero de 2016 - A punto de ahogarse, se hizo un selfie y lo envió a los amigos - About to drown, he took a selfie and sent it to friends - Prestes a se afogar, ele tirou uma selfie e a enviou para amigos

Fig. 32. El Roto, El País, 19 de marzo de 2016 - Votad lo que queráis, os gobiernan algoritmos Vote however you want, you are governed by algorithms - Vote como quiser, você é governado por algoritmos

Fig. 33. El Roto, El País, 20 de diciembre de 2019 - Nos adelantamos a vuestros deseos y os decimos cuáles son - We anticipate your wishes and tell you what they are - Antecipamos seus desejos e dizemos 0 que são

Fig. 34. El Roto, El País, 2 de febrero de 2019 - Una pantalla es una ventana; muchas pantallas, un muro - A screen is a window, many screens are a wall - Uma tela é uma janela, muitas telas são uma parede

Fig. 35 El Roto, El País, 20 de diciembre de 2019 - Antes, mi novio y yo hacíamos el amor, ahora nos intercambiamos archivos - Before, my boyfriend and I made love, now we exchange files - Antes, eu e meu namorado fizemos amor, agora trocamos arquivos

Fig. 36. El Roto, El País, 5 de mayo de 2018 - Los padres son una aplicación del móvil - Parents are an app. of the pone - Os pais são uma app. do de celular

Fig. 37. El Roto, El País, 20 de octubre de 2018 - La educación es una preparación para los videojuegos- Education is a preparation for video games - Educação é uma preparação para videogames

Fig. 38. El Roto, El País, 9 de febrero de 2018 - Para poder ser libre, hay que estar bien programado To be free you have to be well programmed - Para ser livre você tem que estar bem programado

Fig. 39. El Roto, El País, 25 de marzo de 2015 - Las conexiones nos aíslan! - Connections isolate us As conexões nos isolam 
Fig. 41. El Roto, El País, 22 de enero de 2019 - Estoy pensando en dejar la Redes - ¡Demasiado tarde!I'm thinking about leaving the net. It's too late for that now! - Estou pensando em deixar as redes. Tarde demais

Fig. 42. El Roto, El País, 7 de junio de 2011 - Me estoy buscando en Internet para saber quién soy - I am looking myself on the Internet to know who I am - Me estoy buscando en Internet para saber quién soy.

Fig. 44. El Roto, El País, 11 de enero de 2019 - Apagué el ordenador cuando descubrí que intentaba darme órdenes - I turned off the computer when I found out that he was trying to give me orders Desliguei o computador quando descubri que ele estava tentando me dar ordens

Fig. 45. El Roto, El País, 7 de mayo de 2017 - La verdad es un algoritmo - The truth is an algorithm $A$ verdade é um algoritmo 